\title{
Impaired Autophagy and Defective Mitochondrial Function: Converging Paths on the Road to Motor Neuron Degeneration
}

\author{
Brittany M. Edens ${ }^{1,2}$, Nimrod Miller ${ }^{1,2}$ and Yong-Chao Ma ${ }^{1,2 *}$ \\ ${ }^{1}$ Departments of Pediatrics, Neurology, and Physiology, Northwestern University Feinberg School of Medicine, Chicago, \\ IL, USA, ${ }^{2}$ Lurie Children's Hospital of Chicago, Chicago, IL, USA
}

OPEN ACCESS

Edited by:

Manoj Kumar Jaiswal, Columbia University Medical Center,

USA

Reviewed by:

Paula I. Moreira, University of Coimbra, Portugal Yu Aaron Tang, University of Texas Southwestern Medical Center, USA

*Correspondence: Yong-Chao Ma ma@northwestern.edu

Received: 25 November 2015 Accepted: 08 February 2016 Published: 03 March 2016

Citation:

Edens BM, Miller N and Ma YC (2016) Impaired Autophagy and Defective Mitochondrial Function: Converging Paths on the Road to

Motor Neuron Degeneration.

Front. Cell. Neurosci. 10:44.

doi: 10.3389/fncel.2016.00044
Selective motor neuron degeneration is a hallmark of amyotrophic lateral sclerosis (ALS). Around $10 \%$ of all cases present as familial ALS (FALS), while sporadic ALS (SALS) accounts for the remaining $90 \%$. Diverse genetic mutations leading to FALS have been identified, but the underlying causes of SALS remain largely unknown. Despite the heterogeneous and incompletely understood etiology, different types of ALS exhibit overlapping pathology and common phenotypes, including protein aggregation and mitochondrial deficiencies. Here, we review the current understanding of mechanisms leading to motor neuron degeneration in ALS as they pertain to disrupted cellular clearance pathways, ATP biogenesis, calcium buffering and mitochondrial dynamics. Through focusing on impaired autophagic and mitochondrial functions, we highlight how the convergence of diverse cellular processes and pathways contributes to common pathology in motor neuron degeneration.

Keywords: autophagy, mitochondria, calcium homeostasis, protein aggregation, ATP biogenesis, oxidative stress, ALS, motor neuron disease

\section{INTRODUCTION}

Amyotrophic lateral sclerosis (ALS) is an adult-onset neurodegenerative disease characterized by loss of large motor neurons in the brain and spinal cord, resulting in progressive voluntary muscle wasting and respiratory failure. Patient death typically ensues 3-5 years following symptom onset (Volonte et al., 2015). With a prevalence of four-to-six per 100,000 people affected worldwide, ALS is one of the most common neurodegenerative disorders (Tan et al., 2007). Its origins can be either familial or sporadic, of which familial forms account for a mere $10 \%$ whereas the remaining $90 \%$ are sporadic (Rotunno and Bosco, 2013). Although ALS was first described by Charcot as early as 1869 (Jay, 2000), it wasn't until more than a century later that the first casual mutation was identified in copper zinc superoxide dismutase 1 (SOD1; Rosen, 1993). Since then, a multitude of genes associated with ALS pathogenesis have been identified. Nonetheless, mechanisms underlying motor neuron-specific vulnerability in ALS remain largely unknown. At present the disease defies all treatment. Riluzole is the only FDA-approved drug for treating ALS, and it may prolong patient lifespan by mere months (Rowland and Shneider, 2001).

Despite the heterogeneous and multigenic nature of ALS, overlapping pathology and common phenotypes are observed in different forms of the disease. Protein aggregates found in ALS patients suggest that cellular clearance mechanisms, such as the autophagy-lysosome pathway, 
may be impaired in this disease (Blokhuis et al., 2013). Moreover, increased oxidative stress and compromised mitochondrial function are observed in ALS disease condition (Wang and Michaelis, 2010). Intriguingly, oxidative stress is a potent regulator of autophagy (Scherz-Shouval et al., 2007; Huang et al., 2011; Scherz-Shouval and Elazar, 2011), suggesting the potential for functional interactions between the lysosomal and mitochondrial pathways.

Herein, we will consider in depth the dysregulation of autophagy and mitochondrial pathways, as well as their interactions in the context of ALS pathogenesis. We will put a special emphasis on mitophagy, as it directly connects cellular clearance mechanisms with mitochondrial function. Then, we will review the wealth of information regarding mitochondrial dysfunction in ALS, with particular interest in data derived from various mouse models. Lastly, we will discuss the role of oxidative stress as a critical regulator linking these discrete processes, and consider the therapeutic implications for ALS.

\section{MECHANISMS OF CELLULAR CLEARANCE IN PHYSIOLOGICAL AND PATHOLOGICAL CONDITIONS}

\section{Autophagy}

Autophagy is a catabolic process by which cells degrade and recycle cellular constituents through lysosomes to balance sources of energy and building blocks in order to maintain cellular homeostasis and function (Ryter et al., 2013; Yang et al., 2013). The core autophagy machinery consists largely of autophagy-related (ATG) genes, of which ATG1-10, ATG12-16, and ATG18 are all required (Klionsky et al., 2003; Mizushima et al., 2011). Beginning with induction, autophagy is initiated by intracellular or extracellular stimuli such as nutrient deprivation or stress. The most upstream player in the induction process is ATG1, whose mammalian homologs are unc51-like kinase 1 and 2 (ULK1 and 2; Mizushima, 2010). ULK1 interacts with Atg13, FIP200 (focal adhesion kinase family interacting protein of $200 \mathrm{kD}$ ), and ATG101 to form an autophagyinitiating complex (Hara et al., 2008; Hosokawa et al., 2009).

A major regulatory event in autophagy induction is exerted by the initiation complex's interactions with the nutrient-sensing mTOR kinase, and the energy-sensing AMP-activated protein kinase (AMPK). AMPK, activated by a drop in cellular energy, phosphorylates ULK1 on Serine 317 and Serine 777 (Hawley et al., 1996; Egan et al., 2011). These phosphorylation events in turn activate ULK1, which initiates autophagy (Egan et al., 2011). Conversely, the presentation of nutrients activates mTORC1 (through amino acid binding), which phosphorylates ULK1 on Serine 757, leading to the inhibition of autophagy (Kim et al., 2011). Therefore, autophagy initiation is kept in check by both nutrient- and energy-sensing mechanisms.

Following induction, the autophagosome forms and sequesters substrates for degradation. Autophagosome formation is controlled by ATG5 and ATG12/ATG16, which conjugate to recruit LC3 (microtubule-associated protein
1A/1B-light chain 3), a well-established autophagosomal marker (Romanov et al., 2012). In addition, a protein complex consisting of Beclin1, ATG14L and VPS34, a class III phosphoinositide 3-kinase (PI3K), has also been shown to play a critical role in autophagosome formation by serving as a scaffold to recruit autophagy targets to the autophagosome lumen (Volinia et al., 1995; Obara and Ohsumi, 2011). The active ULK1 initiation complex positively regulates autophagy at this level by phosphorylating Beclin-1 on Serine 14 to promote the activity of VPS34 (Russell et al., 2013).

The process of autophagy is completed when the mature autophagosome docks to and fuses with the lysosome, where its cargo are degraded to release energy and cellular building blocks (Mizushima, 2007; Figure 1). This pathway and many of its key molecular constituents are highly conserved throughout evolution, indicating the vital importance of autophagic functions. The most pertinent functions of autophagy include clearance, which eliminates damaged organelles and long-lived proteins that would otherwise compromise cellular health; and catabolism, which releases energy and building blocks to support the growth and activity of the cell (Singh and Cuervo, 2011).

\section{Cellular Clearance and Neurodegeneration}

Though the process of autophagy is ubiquitous throughout a diversity of cells and species, its importance in neurons has become increasingly apparent (Wang and Hiesinger, 2012; Yang et al., 2013). Degradative pathways are essential to maintain balances of cellular energy and stress to promote homeostasis (Ryter et al., 2013); demands on homeostatic regulation are particularly high in neuronal tissue (Chen et al., 2012; Le Masson et al., 2014). As a hallmark of numerous neurodegenerative diseases, the formation of neuronal aggregates highlights the importance of protein clearance in maintaining neuronal health (Polymenidou and Cleveland, 2012; Lim and Yue, 2015). Common to all patients as well as models of ALS is the presentation of pronounced protein inclusions, despite the complex genetic state and broad spectrum of associated mutations involved in the disease. Proteins associated with these aggregates include FUS, TDP-43, UBQLN2 and SOD1, among others (Deng et al., 2011b; Blokhuis et al., 2013). These aggregates may exhibit toxic properties in addition to afflicting the cell by maintaining long-lived proteins (Sau et al., 2007; Johnson et al., 2008; Xu et al., 2013; Wu et al., 2014), as demonstrated in SOD1 mutant mice, where aggregation was shown to drive toxicity in motor neurons. The potency of this toxicity was exacerbated by proteasomal dysregulation (Bruijn et al., 1998; Kitamura et al., 2014).

Decreased efficiency of autophagy, as suggested by the presentation of aggregates, has long been correlated with neurodegeneration. However, a causative relationship between defective autophagy and neurodegeneration was not established until the independent findings that neuronal dysfunction and pathology follow the loss of either Atg5 or Atg8 in mouse (Hara et al., 2006; Komatsu et al., 2006). In both studies, knockout was restricted to the nervous system. Both Atg5- and 

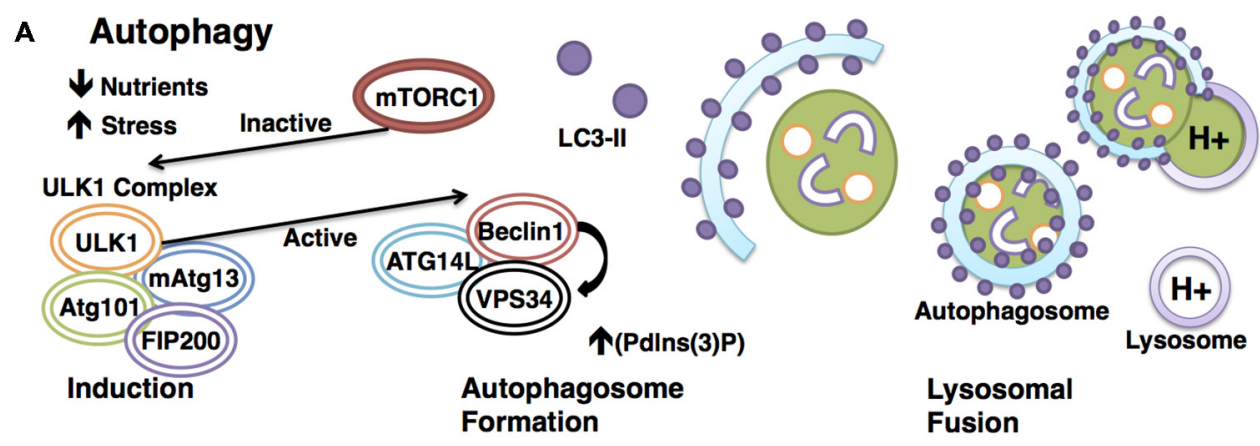
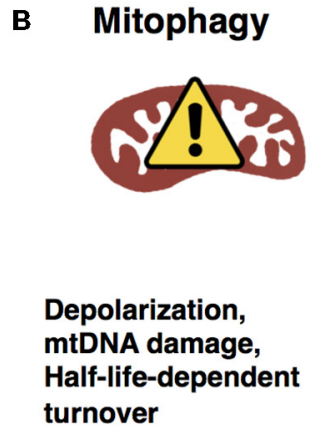

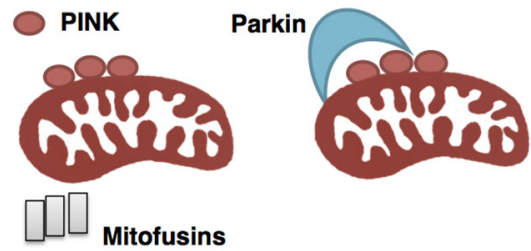

Accumulation of
PINK1,
Loss of Mitofusins

\section{Recruitment of Parkin}

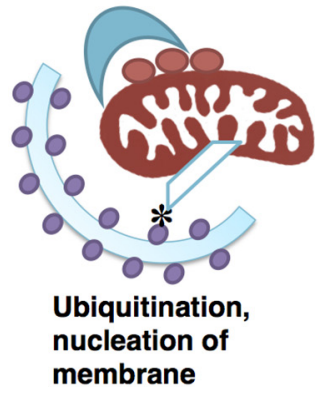

FIGURE 1 | Degradative pathways are tightly regulated. (A) Autophagy is a highly regulated catabolic process. Induction is triggered by physiologically relevant events, such as a drop in nutrients or a rise in stress. mTORC1 represses induction through interaction with the ULK1 initiation complex until an appropriate signal is sensed, at which point mTORC1 rapidly dissociates to allow the activation of the ULK1 complex. The activated ULK1 complex goes on to phosphorylate Beclin1, which in turn positively regulates the activity of VPS34. This results in increased (Pdlns(3)P), a requirement for autophagosome formation. The LC3-II-studded autophagosome membrane then envelops cytoplasm before docking to and fusing with the acid hydrolase-containing lysosome, a process that will enable degradation of the sequestered cytoplasmic materials. (B) Mitophagy requires the canonical autophagy pathway constituents with the addition of mitochondrial-specific adaptors to confer specificity. Targeting of mitochondria for degradation in the PINK1-Parkin-dependenr pathway illustrated here begins with depolarization. Polarization-dependent cleavage of PINK1 is halted, allowing the kinase to accumulate on the outer membrane and recruit the E3 ubiquitin ligase Parkin. PINK1 phosphorylates Parkin, and Parkin ubiquitinates mitochondrial outer-membrane proteins, such as mitofusins. Ubiquitination allows for the docking of adaptor proteins such as optineurin, which recruits LC3 to the targeted mitochondrion to form the autophagosome.

Atg8-deficient mice presented with similar phenotypes: profound motor impairment was noted by 3 and 4 weeks of age, manifesting as impaired coordination, poor balance and reduced grip strength. Moreover, both models exhibited the limb-clasping reflex upon suspension, an aberrant behavior noted previously in rodent models of neurodegeneration. Upon histological analysis, brains from both models revealed a high degree of cellular degeneration, accompanied by ubiquitin-positive inclusions and the accumulation of ubiquitinated proteins. These findings strongly suggest that the reduction of basal protein turnover is sufficient to render cells vulnerable to degeneration.

The link between inefficient protein clearance and neurodegeneration is further illustrated by the nature of the mutations resulting in pathological states. Mutations identified in UBQLN2 have been linked to ALS/FTD (Deng et al., 2011b), as well as a more heterogeneous spectrum of neurodegenerative diseases more recently (Fahed et al., 2014). Aggregation of ubiquilin2 protein is found not only in individuals afflicted with heritable UBQLN2 mutations, but also in unrelated sporadic ALS patients and mouse models, suggesting a general role for UBQLN2 in ALS pathogenesis (Deng et al., 2011a). Ubiquilins are ubiquitin-like proteins implicated in regulating autophagy, as well as the ubiquitin proteasome system (UPS; Zhang et al., 2014). They have been shown to colocalize with autophagosomes and associate with LC3 (N'Diaye et al., 2009); furthermore, reduction of ubiquilin levels correlates with a decrease in autophagosome number, suggestive of a critical role in autophagosome formation (Rothenberg et al., 2010). Precisely how and to what extent ubiquilins participate in autophagy, and what implications this has for ALS pathology are exciting questions requiring further attention.

p62/SQSTM1 is another ALS-associated gene involved in degradative pathways (Teyssou et al., 2013). Like UBQLN2, it is associated with both the UPS and autophagy. In the ubiquitin pathway, p62 delivers polyubiquitinated substrates to the proteasome (Seibenhener et al., 2004). In autophagy, p62 interacts directly with LC3 and ATG8 to confer specificity of targeting by selectively acquiring a subset of polyubiquitinated proteins (Pankiv et al., 2007). Just as ubiquilin2-positive inclusions have become a general observation in both familial and sporadic ALS, so have p62-positive inclusions (Mizuno et al., 2006; Deng et al., 2011a), thus signifying the requirement for protein clearance pathways in the maintenance of neuronal health (Fecto and Siddique, 2012). 
In recent years mutations in chromosome 9 open reading frame 72 (C9orf72) have emerged as the most common cause of both sporadic and familial ALS (DeJesus-Hernandez et al., 2011; Renton et al., 2011). Though much about this peculiar gene awaits characterization, it is proposed to function as a small GTPase Rab GEF (Guanine Nucleotide Exchange Factor), and has been recently implicated in endosomal trafficking (Zhang et al., 2012; Farg et al., 2014). Furthermore, C9orf72 colocalizes with ubiquilin2 and LC3-positive vesicles, as well as autophagy-related small GTPase Rabs, suggesting a potential role in autophagy. Further studies of C9orf72 will be necessary to elucidate its function in this process, as well as suggest a mechanism of pathogenesis in ALS.

\section{Mitophagy}

Mitophagy refers to the selective process whereby mitochondria are targeted and degraded by the autophagy machinery, primarily for the purpose of eliminating defective organelles. Though the key components and sequence of events are largely conserved between mitophagy and autophagy, mitophagy requires additional mitochondrial-specific adaptors to ensure specificity of targeting (Kim et al., 2007).

The best-studied mitophagy pathway is mediated by PTENinduced putative protein kinase 1 (PINK1) and Parkin. Mutations in PINK1 and PARK2, the gene encoding Parkin, result in pronounced mitochondrial dysfunction, leading to degeneration of muscle and neurons (Poole et al., 2008; Jin and Youle, 2012; Figure 1). The finding that overexpression of Parkin is sufficient to mitigate PINK1 mutant phenotypes suggests interaction in the same pathway, with PINK1 upstream of Parkin (Greene et al., 2003; Pesah et al., 2004; Clark et al., 2006). PINK1 is a serine/threonine kinase that associates with mitochondria via a conserved targeting sequence. In healthy mitochondria, PINK1 is imported from the outer to the inner membrane where it is cleaved in a membrane polarization-dependent manner (Deas et al., 2011). When the mitochondrial membrane potential is compromised, PINK1 can no longer be cleaved, thus it accumulates on the outer membrane (Narendra et al., 2010), serving as a signal for recruitment of the E3 ubiquitin ligase Parkin (Vives-Bauza et al., 2010; Shiba-Fukushima et al., 2012). PINK then phosphorylates Parkin and ubiquitin, which is required for Parkin's E3 ligase activity (Koyano et al., 2014). The mechanism underlying phosphorylated ubiquitin activation of Parkin has recently been elucidated (Wauer et al., 2015), following the crystallization of the complex comprising Parkin and phosphorylated ubiquitin. Structural analysis revealed that the binding of phosphorylated ubiquitin to Parkin results in a conformational change within the RING domain, which ultimately results in the activation of Parkin. Importantly, Parkin's ubiquitin binding pocket is commonly mutated in autosomal-recessive Parkinson's, indicating the vital nature of this interaction in promoting mitophagy.

The downstream events that link the targeting of depolarized mitochondria by PINK1-Parkin to the canonical autophagy core machinery are not yet entirely clear. Direct interaction of Parkin with Beclin1 represents one possible explanation (Khandelwal et al., 2011; Lonskaya et al., 2013). Additionally, Parkin has been demonstrated to recruit the Beclin1 regulator AMBRA1 (Activating molecular in BECN1-regulated autophagy protein 1) to the outer membrane of depolarized mitochondria, an event that could also activate the Beclin 1 complex and the core autophagy machinery (Van Humbeeck et al., 2011). Interestingly a role for PINK1 was recently discovered in the recruitment of the autophagy receptors optineurin and NDP52 to depolarized mitochondria. This was shown to activate mitophagy in a Parkinindependent manner, whereby optineurin and NDP52 recruit ULK1 and other autophagy factors (Lazarou et al., 2015).

A number of PINK1-Parkin-independent mechanisms of mitophagy have been described. A reduction in iron, for example, has been shown to promote a distinct pathway that does not rely on PINK1-Parkin. This novel pathway involves the transition from oxidative phosphorylation (OXPHOS) to glycolysis and induction of mitophagy without compromising membrane polarization. Importantly, PINK1 stabilization is not required for this process; iron chelation-induced mitophagy is efficiently activated in fibroblasts deficient in Parkin (Allen et al., 2013). Another PINK1-Parkin-independent pathway is suggested by findings on AMBRA1: Parkin is not required for a distinct form of ABMRA1-mediated mitophagy. Though AMBRA1 is known to interact with Parkin, which is thought to contribute to canonical PINK1-Parkin-mediated mitophagy, it has been shown that mitochondrial-targeted AMBRA1 is sufficient to induce mitophagy in a Parkin-free system, therefore representing a novel mitophagic pathway (Strappazzon et al., 2015). Finally, a mechanism of PINK1-Parkin-independent hypoxiainduced mitophagy has been identified. The mitochondrial outer-membrane protein FUNDC1, FUN14 domain-containing protein 1 , is a mitophagy receptor requiring LC3 interaction. Either knockdown of FUNDC1 or mutation of its LC3-binidng domain significantly hinders hypoxia-induced mitophagy (Liu et al., 2012). Given our growing knowledge of the roles mitochondrial quality control plays in neuronal maintenance, further elucidation of mitophagic pathways will be necessary to advance our understanding and treatment of neurodegenerative disease.

The strongest evidence supporting the contribution of impaired mitophagy to ALS pathogenesis lies in the associated mutations. The involvement of optineurin, encoded by the OPTN gene, in ALS pathogenesis was identified years after the gene had been implicated in primary open-angle glaucoma (Maruyama et al., 2010). Optineurin is involved in a number of cellular processes including Golgi maintenance and membrane trafficking, but its function as an autophagy receptor is presumably the most relevant to ALS pathogenesis (Turturro et al., 2014). Recently, optineurin was shown to play a significant role in PINK1-Parkin-mediated mitophagy. Damaged mitochondria are initially targeted by the E3 ubiquitin ligase Parkin, which ubiquitinates outer membrane proteins such as mitofusins, the outer membrane-embedded GTPases responsible for mediating mitochondrial fusion (Poole et al., 2010). Optineurin then binds to the ubiquitinated mitochondrial outer membrane proteins with its ubiquitin-binding domain. Hereafter, optineurin induces nucleation of the autophagosome 
by recruitment of LC3. ALS-causing mutations in OPTN disable this process, implicating inefficient mitochondrial clearance in ALS (Wong and Holzbaur, 2014). It is intriguing that, much like ubiquilin2 and p62, optineurin has been localized to inclusions in both familial and sporadic ALS (Blokhuis et al., 2013), suggesting a broader role for optineurin, and mitophagy, in ALS pathogenesis.

Valosin containing protein (VCP) mutations have been linked with ALS and other degenerative diseases, including dementia (Johnson et al., 2010; Koppers et al., 2012). VCP is a type II ATPase involved in a broad spectrum of biological processes ranging from proteasomal degradation and mitochondrial quality control via mitophagy, to endoplasmic reticulum (ER)associated degradation (Dai and Li, 2001; Rabinovich et al., 2002; Wojcik et al., 2006; Ju et al., 2009). VCP lies downstream of the E3 ubiquitin ligase Parkin and is recruited to the outer membrane of damaged mitochondria. Degeneration-associated mutant VCP or loss of VCP results in the failure of PINK1-Parkin-mediated mitochondrial clearance. Moreover, VCP has been demonstrated to regulate the proteasomal degradation of mitofusins (Kim et al., 2013). Altogether, the role of optineurin and VCP in mitochondrial quality control supports dysregulation of mitophagy as a critical mechanism in ALS pathogenesis.

Very recently, two independent studies identified a definitive link between TBK1, TANK Biding Kinase 1, and ALS, citing a loss-of-function mechanism-of-action (Cirulli et al., 2015; Freischmidt et al., 2015). Substrates of TBK1 include optineurin as well as p62, thus strengthening the connection between mitophagic function and motor neuron degeneration in ALS. Indeed, mutations resulting in disruption of the C-terminal coiled-coiled optineurin-interacting domain of TBK1 were linked with pathogenesis, suggesting a vital role for the kinase in the regulation of mitophagy. Accordingly, a recent study has elucidated the mechanism by which TBK1 acts in mitophagy (Heo et al., 2015). PINK1-Parkindependent phosphorylation of TBK1 activates the kinase to recruit autophagy receptors optineurin and NDP52 to the depolarized mitochondrion. TBK1 phosphorylates these receptors, and in turn, optineurin binding to polyubiquitin chains on the mitochondrial outer membrane enhances TBK1 activation, thus amplifying the mitophagic signal. Importantly, TBK1-dependent phosphorylation of optineurin increases its affinity for polyubiquitin binding, and this step is required for efficient mitophagy. Altogether, these findings put forth a novel framework within which TBK1 plays an integral role in amplifying the mitophagic signal via enhanced recruitment and activation of autophagy receptors on depolarized mitochondria, linking dampened mitophagy with ALS pathogenesis.

\section{MITOCHONDRIAL FUNCTION: IMPAIRMENTS IMPLICATED IN ALS}

\section{ATP Generation}

ATP is produced in mitochondria through OXPHOS of glucose via the electron transport chain (ETC). In this process, electrons pass along a sequence of protein complexes (I-IV) located in the inner mitochondrial membrane (Milstein and Swaiman, 1968). A flow of protons is pumped from the matrix into the inter-membrane space, generating an electrochemical gradient. When protons flow from high to low concentration through ATP synthase on the inner mitochondrial membrane, ADP is converted to ATP, storing high-energy in a phosphate bond for later use. Linking ATP biogenesis with ALS, a computational modeling endeavor suggested a framework within which mitochondrial dysfunction driving reduced ATP availability underlies motor neuron susceptibility to degeneration. According to this model, ATP reduction drives hyperexcitability through mechanisms such as $\mathrm{Na}^{+} / \mathrm{K}^{+}$ dyshomeostasis, and intracellular calcium hikes (Le Masson et al., 2014).

Reduced ETC activity has likewise been described in both patients and models of ALS, and may significantly contribute to pathogenesis. Compared to healthy controls, ALS-derived fibroblasts show altered mitochondrial bioenergetics: membrane potential is significantly reduced in correlation with age of onset, and an overall decrease in mitochondrial content is noted when compared to controls (Kirk et al., 2014). In line with these findings, a mutant SOD1-mediated switch from OXPHOS to glycolysis has been reported, indicative of inefficient ATP biogenesis in ALS (Allen et al., 2014). Direct genetic evidence of this comes from the recent identification of mutations in CHCHD10 causing ALS and frontotemporal dementia (Bannwarth et al., 2014; Chaussenot et al., 2014). Though the functional repertoire of $\mathrm{CHCHD} 10$ awaits further elucidation, it is predicted to play a significant role in energy production through OXPHOS (Bannwarth et al., 2014).

The wealth of data leading to our current understanding of mitochondrial dysfunction in ALS originates from reports on the SOD1 class of mutations (Bendotti and Carri, 2004). These mutations are the most widely studied in ALS, as SOD1 was the first identified FALS-linked gene (Rosen et al., 1993). Wild-type SOD1 is found predominantly in the cytoplasm where it neutralizes the damaging effects of reactive oxygen species (ROS; Fukai and Ushio-Fukai, 2011). A small amount of SOD1 is localized to the mitochondrial inter-membrane space (Jaarsma et al., 2001) where it is suggested to play a protective role in motor neurons (Waterman-Storer et al., 1997). ALS-associated mutations lead to increased localization of misfolded SOD1 protein to the mitochondrial inter-membrane space (Liu et al., 2004; Deng et al., 2006), and mutant SOD1-mitochondrial interactions lead to the alteration of mitochondrial redox potential (Ferri et al., 2006). Accumulation of SOD1 mutant aggregates has been shown to lead to dysfunctional mitochondria with decreased ATP production, calcium buffering and motility defects (Cozzolino and Carri, 2012). Furthermore, OXPHOS activity is impaired in both ALS patients and SOD1 mutant transgenic mice (Bacman et al., 2006). Reduced levels of respiratory chain activity in complexes I-IV were observed in spinal cord tissue collected from ALS patients (Wiedemann et al., 2002). In the SOD1 $1^{G 93 A}$ 
mouse model, a pre-symptomatic decrease in Complex I function was noted, while Complex IV was found to be impaired following ALS-like symptom onset (Jung et al., 2002).

\section{Calcium Buffering}

In motor neurons, mitochondria must meet not only high energy demands but also considerable calcium buffering requirements. Healthy mitochondria have enormous calcium buffering capacity and are able to effectively travel from areas of low calcium to areas of high calcium to restore normal levels (Wang and Schwarz, 2009). When mitochondria sense an increase in calcium they become stationary by arresting mitochondrial movement (Rintoul et al., 2003; Szabadkai et al., 2006). As one of the most eminent second messengers in neuronal cells, calcium is required by neurons for neurotransmitter release, modulation of synaptic efficiency, and signal transduction. Unregulated accumulation of calcium proves toxic to cells, however. In neurons, when excitatory glutamate receptors become excessively stimulated, high levels of calcium flow into the cell, leading to cell damage and death (Carriedo et al., 2000; Corona and Tapia, 2007). How calcium mediates this effect is not entirely understood, but its role in enzymatic and signaling cascade activation is one possible explanation.

Dysregulation of calcium homeostasis has been extensively reported in ALS, particularly as it pertains to SOD1 mutation (Jaiswal and Keller, 2009). There have been reports of chronic calcium overload in mitochondria at nerve terminals (Siklós et al., 1996), and SOD1 mutant mouse nerve terminals were shown to be depolarized as a result (Nguyen et al., 2009). Additionally, decreases in calcium loading capacity occur in the spinal cord and brain of mutant SOD1 mice (Damiano et al., 2006). Calcium dysregulation was also linked to SOD1 mutant protein aggregation and impaired mitochondrial movement (Tradewell et al., 2011). Therefore, excitotoxicity following calcium dysregulation is posited to be a prominent mechanism in ALS pathogenesis (Van Den Bosch et al., 2006). While widely supported, this view faces opposition from a study identifying early (presymptomatic), but not late (endstage) hyperexcitability in the context of altered calcium handling (Fuchs et al., 2013). Such findings therefore call into question the role of hyperexcitability in motor neuron cell death.

Motor neurons exhibit a low calcium buffering capacity, largely the result of sparse calcium buffering protein expression (Celio, 1990; Ince et al., 1993; Palecek et al., 1999). Moreover, calcium handling and buffering capacity are impaired in models of ALS (Jaiswal et al., 2009; von Lewinski et al., 2008). Whereas proteins such as parvalbumin and calbindin are abundant in degeneration-resistant neuronal subtypes, conferring more stable calcium homeostasis (Vanselow and Keller, 2000), expression is comparatively limited in the motor neurons affected in ALS (Elliott and Snider, 1995). What is more, the intracellular free calcium increase noted in $S O D 1^{G 93 A}$ transgenic mice at both late presymptomatic and symptomatic stages was correlated with decreased expression of calcium-buffering proteins such as SERCA1, SERCA2, and parvalbumin (Chin et al., 2014). Additionally, calciumpermeable $\alpha$-Amino-3-hydroxy-5-methyl-4-isoxazolepropionic acid receptor (AMPAR) expression, especially those lacking the GluR2 subunit, is particularly high in motor neurons, permitting heightened calcium influx (Lips and Keller, 1998; Van Damme et al., 2002). This may contribute to the susceptibility of cultured motor neurons to AMPAR-mediated excitotoxicity upon overstimulation (Carriedo et al., 1996, 2000; Corona and Tapia, 2007). Accordingly, the anti-excitotoxic drug, Riluzole, is at present the only agent approved for the treatment of ALS, which functions by blocking AMPA receptors, thus inhibiting glutamate release and regulating calcium levels in the cytosol (Bellingham, 2011). When tested in the SOD1 mutant mouse model, Riluzole showed an increase in survival (Gurney et al., 1996), but in patients it has been shown to expand life by only several months on average (Bensimon et al., 1994; Lacomblez et al., 1996). It is worth noting that, despite the well-established role of altered calcium handling in ALS, enhanced buffering as achieved by elimination of cyclophilin D was insufficient to extend survival in SOD1 mouse models, in spite of improved motor neuron survival and reduced SOD1 aggregation (Parone et al., 2013).

\section{Mitochondrial Transport}

Motor neurons innervate muscle fibers great distances away from the soma, which requires mitochondria to be continually transported along the axon to areas of high energy and calcium buffering demand. Defects in mitochondrial transport render neurons especially vulnerable to degeneration (De Vos et al., 2008; Wang and Schwarz, 2009). Mitochondria utilize many different motor proteins to move in a saltatory manner, which enables their recruitment to areas of low ATP where they remain docked due to high levels of ADP that halt movement (Mironov, 2007). Generally, about one-third of mitochondria are in motion while two-thirds are stationary (Sheng, 2014). Mitochondria travel along microtubules either away from the soma (anterograde) or towards the soma (retrograde). Kinesins are generally responsible for anterograde travel whereas dynein facilitates retrograde transport (Forman et al., 1983). Other key players in mitochondrial transport include dynactin (WatermanStorer et al., 1997), syntaphilin (Kang et al., 2008), and the Milton-Miro complex (Stowers et al., 2002; Figure 2). Intriguingly, neuronal-restricted loss of Miro culminates in brain stem and spinal cord atrophy resembling motor neuron disease, suggesting a requirement for mitochondrial mobility in motor neuron health and maintenance (Nguyen et al., 2014).

Mitochondria in the ALS-linked SOD1 mutant mouse model experience axonal transport deficits before ALS symptoms arise, resulting in a deficiency of axonal mitochondria (De Vos et al., 2007). Multiple studies have shown impairment in anterograde and retrograde transport (Bilsland et al., 2010; Magrané et al., 2012; Marinkovic et al., 2012). Mutant SOD1 is thought to aggregate in mitochondria and bind to dynein, thus disrupting axonal transport (Ligon et al., 


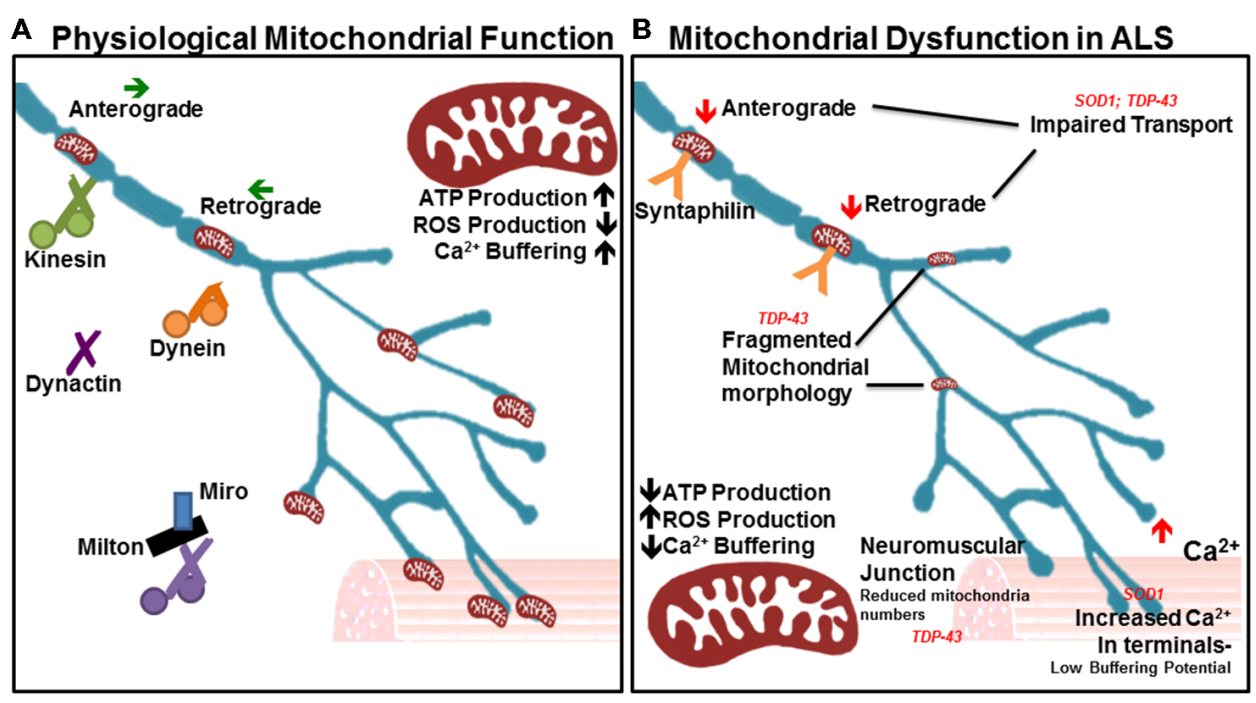

FIGURE 2 | Many aspects of mitochondrial function are impaired in amyotrophic lateral sclerosis (ALS). (A) In physiological states, mitochondria show a high capacity for ATP production and $\mathrm{Ca}^{2+}$ buffering, with low reactive oxygen species (ROS) production. The orderly anterograde and retrograde trafficking of mitochondria along axons by motor proteins ensures that energy and calcium buffering are appropriately mobilized given the local needs throughout the cell and neurites. Milton/Miro and syntaphilin dock mitochondria in accordance with localized energy or buffering needs. Their dense distribution is noted in the neuromuscular junction, as well as other areas of high $\mathrm{Ca}^{2+}$ and metabolic demand. (B) In ALS, mitochondrial ATP production and Ca ${ }^{2+}$ buffering capacity are reduced, while ROS production is elevated. Accordingly, $\mathrm{Ca}^{2+}$ levels are heightened in motor nerve terminals. Impairments in axonal transport of mitochondria are noted, as is a depletion of the mitochondrial population at the neuromuscular junction. Mitochondrial morphology is also irregular in diseased motor neurons, indicating poor health and inefficient turnover.

2005; Zhang et al., 2007). This can prevent mitochondria from being recruited to areas of high energy or calcium buffering demand, and can also stop defective mitochondria from being trafficked back to the soma. Importantly, such an interaction would affect all axonal transport pathways. Recent studies in the SOD1 $1^{G 93 A}$ model reveal important effects on dynein-mediated transport of late endosomes. Lysosomal dysfunction occurs in a progressive manner and impairs autophagy-mediated degradation prior to symptom onset in the SOD $1^{G 93 A}$ mode. This occurs through mutant SOD1 binding with dynein, which interferes with retrograde trafficking of late endosomes, resulting in autophagic failure (Xie et al., 2015).

Mutations in TARDBP, the gene encoding TDP-43, are causal for ALS and like SOD1, have been shown to affect mitochondrial quality and transport. TDP-43 is a highly conserved, ubiquitously expressed DNA/RNA binding protein involved in a wide range of processes important for RNA metabolism (Baralle et al., 2013; Ling et al., 2013). In ALS, however, it was found to be ubiquitinated, phosphorylated and cleaved into insoluble C-terminal fragments that accumulate in cytoplasmic inclusions (Neumann et al., 2006; Johnson et al., 2009). TDP-43 inclusions are found in neurons and glia in both FALS and SALS, with the exception of patients and models presenting with SOD1 mutations (Mackenzie et al., 2007; Tan et al., 2007). Transgenic mice overexpressing wild type human TDP-43 under the control of the Thy1.2 promoter, which drives expression specifically in neurons, displayed motor defects and shortened life span. Spinal motor neurons exhibited cytosolic inclusions and accumulation of fragmented mitochondria. Furthermore, mitochondria were absent from the neuromuscular junction (Shan et al., 2010). In another study, in vivo imaging of mitochondrial movement in mutant TDP-43 transgenic mice revealed a pre-symptomatic impairment of mitochondrial transport in motor neurons, followed by mitochondrial morphological abnormalities (Magrané et al., 2014). Mitochondrial transport defects in TDP-43 transgenic mice can be attributed to the key role that TDP-43 plays in neurofillament stability (Wang et al., 2008; Volkening et al., 2009). Together, SOD1 and TARDBP mutations support a crucial requirement for mitochondrial activity and axonal transport in motor neuron function and maintenance.

\section{CROSSTALK BETWEEN MITOCHONDRIAL AND AUTOPHAGIC PATHWAYS}

\section{Oxidative Stress and Autophagy Regulation}

ROS are by-products of mitochondrial OXPHOS and include superoxide anion and peroxide, which, as a result of unpaired electrons, are unstable and reactive. ROS can readily react with virtually any macromolecule, thereby posing threat of damage to somatic or mitochondrial DNA, lipids, enzymes and other proteins. High levels of ROS lead to elevated oxidative stress within the cell, which is proposed to underlie a number of pathological states (Afanas'ev, 2005; Jang and Van Remmen, 
2009). Nonetheless, oxidative stress is posited to serve a pertinent function physiologically, as increasing lines of evidence suggest a chief role in autophagy regulation (Scherz-Shouval et al., 2007; Huang et al., 2011; Scherz-Shouval and Elazar, 2011). ROS have been demonstrated to induce autophagy in starvation conditions through a mechanism requiring AMPK activation ( $\mathrm{Li}$ et al., 2013), which drives a ROS-dependent decrease in mTOR activity. The upstream regulation of ROS-induced autophagy entails the cytoplasmic activation of ataxia telangiectasia mutated (ATM) kinase, leading to the activation of AMPK. AMPK phosphorylation of TSC2 ultimately results in inhibition of mTOR kinase (Alexander et al., 2010). Therefore, AMPK activity is required for the inhibition of mTOR, which thereby removes repression from the autophagy initiation complex to allow ULK1 phosphorylation by AMPK, triggering autophagy induction.

Dysfunctional and long-lived mitochondria, which are far more likely to engage in reduced-quality energy production, tend to generate excessive ROS as compared to healthy mitochondria (Chistiakov et al., 2014), thus triggering autophagic induction. This is likely a mechanism evolved to restrict damages caused by oxidative stress. Under physiological conditions, ROS are a vital component of autophagy regulation; however, when the autophagic machinery is not competent to respond, ROS levels go unchecked, presenting oxidizing damage to the cell while failing to elicit the appropriate catabolic response. It has been suggested that oxidative stress-induced dysfunction of the autophagy pathway drives the accumulation of longlived and dysfunctional mitochondria (Luo et al., 2013). Moreover the accumulation of damaged mitochondria results in elevated oxidative stress, further challenging the autophagylysosome pathway in a vicious circle (Figure 3). This appears to be a prominent mechanism at play in ALS, as afflicted patients and models alike show elevated ROS and signs of unchecked oxidative stress (Weiduschat et al., 2014; Ikawa et al., 2015).

\section{Cell Death: The Autophagy Connection}

Though oxidative stress is a signal of vital importance in promoting homeostasis and inducing autophagy, it also has a chief role in regulating cell death (Ryter et al., 2007). In fact, in models of ALS, ROS has been shown to drive motor neuron cell death (Rojas et al., 2015). Dysfunction of the autophagy-lysosome pathway under oxidative stress is a driving force for the accumulation of damaged mitochondria (Luo et al., 2013), which in turn results in heightened oxidative stress. In instances where this signal is excessive or prolonged, it may elicit a form of cell death independent from apoptosis, termed autophagic cell death (Chen et al., 2008; Li et al., 2013). One form of autophagic cell death, autosis, is characterized by independance from caspases and other constituents of pro-death pathways, as well as unique

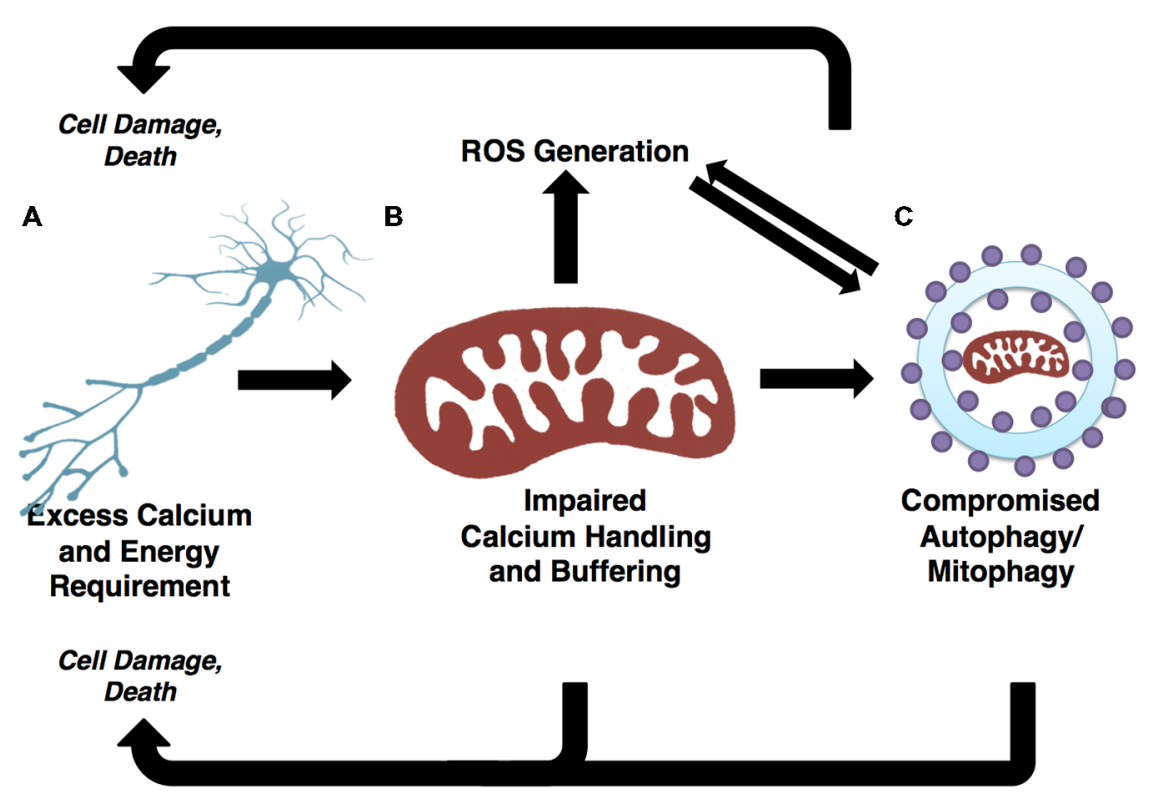

FIGURE 3 | Autophagic and mitochondrial paths to motor neuron death are convergent. (A) Selective motor neuron degeneration is characteristic of ALS. Motor neurons' highly polarized morphology and extensive calcium buffering and energy demands likely underlie this vulnerability. (B) Demands on calcium buffering and energy production are fulfilled by mitochondria. ROS are generated as a byproduct of oxidative phosphorylation (OXPHOS). The generally high metabolic requirements of neuronal cells may contribute to elevated ROS, which in turn results in cellular stress and the potential for mitochondrial dysfunction if mitophagic efficiency is not high. (C) Demands of neuronal mitochondria necessitate frequent turnover through mitophagy pathways. Mitochondrial-derived ROS positively regulate autophagy/mitophagy. If the autophagy/mitophagy machinery becomes impaired, ROS is not reduced and mitochondria are not recycled, thus leading to increases in ROS and cellular stress. The accumulation of ROS has potential to damage DNA, proteins and mitochondria, thereby presenting further challenge to the autophagy/mitophagy machinery. As such, the regulation of autophagy/mitophagy through mitochondrial-derived ROS and mitophagy-dependent mitochondrial quality control illustrate two pathways converging onto selective motor neuron death. 
morphological features including membrane rupture, shrinkage of the nuclear membrane, electron-dense mitochondria and fragmented ER, and strengthened substrate adhesion. The autotic cell death pathway also features a unique reliance on $\mathrm{Na}^{+}, \mathrm{K}^{+}$-ATPases, and can be triggered pharmacologically or by starvation (Liu et al., 2013; Liu and Levine, 2015). This pathway is relevant in vivo, as rodent hippocampal neurons die through autosis following hypoxic-ischemic injury. That treatment with cardiac glycosides, identified in a high-throughput compound screen for autosis inhibitors, robustly rescues autotic cell death in this model suggests therapeutic potential for targeting this pathway (Liu et al., 2013). Though contributions of this pathway to motor neuron death in ALS are uncertain, it is intriguing that $\mathrm{Na}^{+} / \mathrm{K}^{+}$ dyshomeostasis in disease progression has been posited by computational modeling of ALS pathogenesis (Le Masson et al., 2014).

Further evidence concerning additional roles for constituents of the autophagy machinery in traditional caspase-dependent pathways implicates even broader contributions to cell death. For example, cleavage of the autophagy-related gene Atg5 by calpain regulates apoptosis. The cleavage fragment translocates to mitochondria, where it blocks anti-apoptotic Bcl to drive cytochrome-c release and thereby promote caspase-dependent apoptosis (Yousefi et al., 2006). A similar mechanism is supported for Beclin1 in apoptotic induction (Wirawan et al., 2010). Caspase-dependent cleavage of Beclin1 yields a Cterminal fragment that localizes to mitochondria where it potentiates apoptosis, potentially through the release of proapoptotic factors. A role for the autophagy-associated protein ULK1 in promoting cell death, independent of autophagy, has recently emerged. Treatment with $\mathrm{H}_{2} \mathrm{O}_{2}$ facilitates the nuclear localization of ULK1 in an activation-dependent manner. In the nucleus, ULK1 interacts with Poly (ADPRibose) Polymerase 1 (PARP1), thereby increasing its activity and potentiating PARP1-induced cell death (Joshi et al., 2016). Interestingly, ULK1 is a transcriptional target of p53; its expression is upregulated in response to DNA damage, and it contributes to cell death following prolonged autophagy (Gao et al., 2011), suggesting both autophagydependent and-independent forms of ULK1-mediated cell death.

Motor neuron cell death in both familial and sporadic forms of ALS is attributable to necroptosis (Re et al., 2014). Necroptosis is a regulated necrotic form of cell death, independent of caspases, thereby distinguishing this pathway from apoptosis. TNF (tumor necrosis factor) induces necroptosis in a manner requiring the inactivation of caspase-8. This promotes the interaction of RIPK1 and RIPK3 (receptor interacting protein kinases), which is vital for the formation of the necrosome. The MLKL (mixed lineage kinase domain-like) pseudokinase is then recruited to execute necroptosis through an unknown mechanism (Linkermann and Green, 2014; Vanden Berghe et al., 2014). It is intriguing that some lines of evidence point to a chief role for the autophagy machinery in necroptosis. In particular, the Bcl-2 inhibitor GX15-070 promotes cells death through
RIP1-dependent necroptosis, which requires autophagosome accumulation to serve as sites of necrosome assembly. Inhibition of autophagosome formation precludes this mechanism of cell death, highlighting the importance of constituents of the autophagy-lysosome pathway in necroptotic cell death. Interestingly, RIP1 inhibition does not limit GX15-070-mediated autophagosome accumulation, indicating the role of autophagy induction upstream of RIP1 activity in necroptosis (Basit et al., 2013). Altogether, the roles of autophagy in cell death are complex and incompletely understood, and contributions of these pathways to motor neuron death in ALS require further investigation. Nonetheless, that autophagic dysfunction and cell death frequently co-occur in ALS is perhaps no coincidence.

\section{THERAPEUTIC PROSPECTIVE}

\section{Boosting Autophagy}

That protein aggregates are characteristic of ALS and other neurodegenerative diseases suggests that the autophagy pathway may be an attractive therapeutic target for the prevention and treatment of neurodegeneration (Vidal et al., 2014). Indeed, enhancing autophagy has been shown to effectively target ALS-associated pathological aggregates for clearance to reduce toxicity (Hung et al., 2009; Wang et al., 2012; Barmada et al., 2014). The mTORC1 inhibitor rapamycin can effectively induce autophagy by eliminating mTOR-mediated inhibition of the ULK1 autophagy initiation complex (Jung et al., 2009). Rapamycin administration improved prognosis in TDP-43 mutant mice (Wang et al., 2012), but findings from trials with $S O D 1$ or $V C P$-associated inclusion body myopathy mutant models did not suggest a similar beneficial effect (Zhang et al., 2011; Ching et al., 2013). Interestingly, in SOD1 mutant mice lacking mature lymphocytes, a modest survival increase was noted following rapamycin treatment (Staats et al., 2013). This finding suggests the benefit of the autophagypromoting effect of rapamycin, as well as its detrimental effect on protective immune function. In support of this finding, preclinical trials with the autophagy-inducing agent trehalose proved successful in a SOD1 mutant model (Castillo et al., 2013). Trehalose promotes autophagy by transcriptional upregulation of $A T G$ genes through an mTOR-independent pathway.

Although direct defects in autophagy genes may not be the causal link in all cases of ALS, dysfunction of autophagy exacerbates disease phenotypes (Bruijn et al., 1998; Kitamura et al., 2014). Therefore, boosting the efficiency of autophagy could ameliorate the toxic effects of aggregates characteristic of ALS and other neurodegenerative diseases. Nonetheless, it is with some caution that we interpret these results, as there are indications that enhanced autophagy may in some instances further exacerbate axonal degeneration and disease phenotype. For example, autophagy has been implicated as an early requirement for axonal degeneration phenotypes in a number of models, including an excitotoxic neurodegeneration model (Wang et al., 2006). Moreover, 
TABLE 1 | ALS genetics reflect a trend in impaired autophagic and mitochondrial pathways.

\begin{tabular}{lll}
\hline Affected gene & Functional Processes/Impairment in ALS & Reference \\
\hline UBQLN2 & Ubiquitin proteasome system, autophagy & Deng et al. (2011a,b) \\
SQSTM1 & Ubiquitin proteasome system, autophagy & Fecto et al. (2011) \\
C9ORF72 & Repeat expansion, endosomal trafficking, autophagy & DeJesus-Hernandez et al. (2011) and Renton et al. (2011) \\
VAPB & Unfolded protein response, Ca ${ }^{2+}$ regulation & Nishimura et al. (2004a,b) \\
OPTN & Autophagy, mitophagy & Maruyama et al. (2010) \\
VCP & Mitophagy & Johnson et al. (2010) \\
DCTN & Axon transport & Münch et al. (2005, 2004) \\
TARDBP & DNA binding, axon transport & Kabashi et al. (2008) and Kühnlein et al. (2008) \\
SOD1 & Antioxidant activity & Rosen et al. (1993) \\
CHCD10 & Oxidative phosphorylation, Cristae morphology & Bannwarth et al. (2014) and Johnson et al. (2014)
\end{tabular}

ALS-associated genes have functions relevant to degradative and mitochondrial pathways. Specifically, a number of associated genes are involved in the degradative pathways of autophagy/mitophagy and the ubiquitin proteasome system (UPS). Additionally, genes involved in mitochondrial function and quality control indicate the critical importance of mitochondrial health in neuronal maintenance and protection.

the neurite retraction phenotype characteristic of the Parkinsonian $L R R K 2^{G 2019 S}$ mutation implicates autophagic induction as an early event. Accordingly, RNAi-mediated knockdown of autophagy factors LC3 or ATG7 is sufficient to rescue neurite length (Plowey et al., 2008). In addition, it was shown using Atg7-deficient mice that negatively regulating autophagy is sufficient to promote cell survival of hippocampal pyramidal neurons following ischemic insult (Koike et al., 2008). These results, taken together with the expanding roles of autophagy in promoting cell death, indicate that it is the regulated balance of autophagy, not merely increased induction, that promotes neuronal health and protection.

\section{Enhancing Mitochondrial Health}

As increasing evidence suggests a prominent role for mitochondrial dysfunction and oxidative stress in motor neuron degeneration, enhancing mitochondrial health represents a promising strategy for treating ALS and related diseases. In line with this, long-term users of the antioxidant vitamin $\mathrm{E}$ show a decreased risk for ALS (Wang et al., 2011), consistent with findings of elevated ROS levels (Ikawa et al., 2015) and decreased antioxidant levels (Weiduschat et al., 2014) in ALS-afflicted patients. However, most proposed antioxidant treatments for ALS are not beneficial in clinical trials (Graf et al., 2005; Orrell et al., 2008). This lack of success may be attributed to the low efficiency of targeting antioxidants to mitochondria. To circumvent this issue, the cell permeable Szeto-Schiller antioxidant peptide (SS-31) was investigated (Petri et al., 2006; Szeto, 2006). SS-31 is readily taken up by the cell and localizes to the mitochondrial inner membrane. The specific targeting of SS-31 was shown to inhibit ROS generation and protect against oxidative damage (Zhao et al., 2004, 2005). Presymptomatic treatment with SS-31 in a genetic mouse model of ALS improved disease prognosis significantly (Petri et al., 2006). It remains to be determined whether this therapeutic method offers equal potential for additional models of ALS, and how these findings will translate in human trials.

\section{CONCLUSION}

Protein aggregates are chief characteristics of many neurodegenerative diseases, including ALS (Blokhuis et al., 2013). Gain-of-function properties of disease-associated mutations can directly lead to protein aggregation (Sau et al., 2007; Johnson et al., 2008; Xu et al., 2013; Wu et al., 2014). In addition, loss-of-function of Atg genes is sufficient to cause neurodegeneration in mice, suggesting a prominent role for autophagic clearance pathways in neurodegenerative disease (Hara et al., 2006; Komatsu et al., 2006). Consistent with this, many ALS-disease genes are linked to cellular clearance pathways (Deng et al., 2011b; Table 1), and phenotypic improvements have been achieved by enhancing autophagy in some ALS mouse models (Hung et al., 2009; Wang et al., 2012; Barmada et al., 2014). Besides impaired autophagy, defective mitochondrial function, which leads to increased oxidative stress and compromised calcium buffering, also plays a critical role in motor neuron degeneration and ALS pathogenesis. In particular, impaired autophagy and dysfunctional mitochondrial pathways may engage in crosstalk in the onset and progression of ALS. As such, therapeutic strategies targeting these two pathways and their interactions will hold great promise for alleviating disease symptoms and rescuing motor neuron degeneration in ALS and related diseases.

\section{AUTHOR CONTRIBUTIONS}

BME, NM, and YCM conceived of, drafted, edited, and approved the corresponding review.

\section{ACKNOWLEDGMENTS}

This work was supported by NIH grants R01NS094564, AG043970 and grants from the Hartwell Foundation and Whitehall Foundation to YCM. YCM is Ann Marie and Francis Klocke MD Research Scholar supported by the Joseph and Bessie Feinberg Foundation. We thank members of the Ma laboratory for critically reading the manuscript. 


\section{REFERENCES}

Afanas'ev, I. B. (2005). Free radical mechanisms of aging processes under physiological conditions. Biogerontology 6, 283-290. doi: 10.1007/s10522-0052626-z

Alexander, A., Cai, S. L., Kim, J., Nanez, A., Sahin, M., MacLean, K. H., et al. (2010). ATM signals to TSC2 in the cytoplasm to regulate mTORC1 in response to ROS. Proc. Natl. Acad. Sci. U S A 107, 4153-4158. doi: 10.1073/pnas. 0913860107

Allen, S. P., Rajan, S., Duffy, L., Mortiboys, H., Higginbottom, A., Grierson, A. J., et al. (2014). Superoxide dismutase 1 mutation in a cellular model of amyotrophic lateral sclerosis shifts energy generation from oxidative phosphorylation to glycolysis. Neurobiol. Aging 35, 1499-1509. doi: 10.1016/j. neurobiolaging.2013.11.025

Allen, G. F., Toth, R., James, J., and Ganley, I. G. (2013). Loss of iron triggers PINK1/Parkin-independent mitophagy. EMBO Rep. 14, 1127-1135. doi: 10. 1038/embor.2013.168

Bacman, S. R., Bradley, W. G., and Moraes, C. T. (2006). Mitochondrial involvement in amyotrophic lateral sclerosis: trigger or target? Mol. Neurobiol. 33, 113-131. doi: 10.1385/mn:33:2:113

Bannwarth, S., Ait-El-Mkadem, S., Chaussenot, A., Genin, E. C., Lacas-Gervais, S., Fragaki, K., et al. (2014). A mitochondrial origin for frontotemporal dementia and amyotrophic lateral sclerosis through CHCHD10 involvement. Brain 137, 2329-2345. doi: 10.1093/brain/awu138

Baralle, M., Buratti, E., and Baralle, F. E. (2013). The role of TDP-43 in the pathogenesis of ALS and FTLD. Biochem. Soc. Trans. 41, 1536-1540. doi: 10. 1042/BST20130186

Barmada, S. J., Serio, A., Arjun, A., Bilican, B., Daub, A., Ando, D. M., et al. (2014). Autophagy induction enhances TDP43 turnover and survival in neuronal ALS models. Nat. Chem. Biol. 10, 677-685. doi: 10.1038/nchembio.1563

Basit, F., Cristofanon, S., and Fulda, S. (2013). Obatoclax (GX15-070) triggers necroptosis by promoting the assembly of the necrosome on autophagosomal membranes. Cell Death Differ. 20, 1161-1173. doi: 10.1038/cdd.2013.45

Bellingham, M. C. (2011). A review of the neural mechanisms of action and clinical efficiency of riluzole in treating amyotrophic lateral sclerosis: what have we learned in the last decade? CNS Neurosci. Ther. 17, 4-31. doi: 10.1111/j.17555949.2009.00116.x

Bendotti, C., and Carri, M. T. (2004). Lessons from models of SOD1-linked familial ALS. Trends Mol. Med. 10, 393-400. doi: 10.1016/j.molmed.2004. 06.009

Bensimon, G., Lacomblez, L., and Meininger, V. (1994). A controlled trial of riluzole in amyotrophic lateral sclerosis. N. Engl. J. Med. 330, 585-591. doi: 10. 1056/nejm199403033300901

Bilsland, L. G., Sahai, E., Kelly, G., Golding, M., Greensmith, L., and Schiavo, G. (2010). Deficits in axonal transport precede ALS symptoms in vivo. Proc. Natl. Acad. Sci. U S A 107, 20523-20528. doi: 10.1073/pnas.1006869107

Blokhuis, A. M., Groen, E. J., Koppers, M., van den Berg, L. H., and Pasterkamp, R. J. (2013). Protein aggregation in amyotrophic lateral sclerosis. Acta Neuropathol. 125, 777-794. doi: 10.1007/s00401-013-1125-6

Bruijn, L. I., Houseweart, M. K., Kato, S., Anderson, K. L., Anderson, S. D., Ohama, E., et al. (1998). Aggregation and motor neuron toxicity of an ALS-linked SOD1 mutant independent from wild-type SOD1. Science 281, 1851-1854. doi: 10.1126/science.281.5384.1851

Carriedo, S. G., Sensi, S. L., Yin, H. Z., and Weiss, J. H. (2000). AMPA exposures induce mitochondrial $\mathrm{Ca}^{2+}$ overload and ROS generation in spinal motor neurons in vitro. J. Neurosci. 20, 240-250.

Carriedo, S. G., Yin, H. Z., and Weiss, J. H. (1996). Motor neurons are selectively vulnerable to AMPA/kainate receptor-mediated injury in vitro. J. Neurosci. 16, 4069-4079.

Castillo, K., Nassif, M., Valenzuela, V., Rojas, F., Matus, S., Mercado, G., et al. (2013). Trehalose delays the progression of amyotrophic lateral sclerosis by enhancing autophagy in motoneurons. Autophagy 9, 1308-1320. doi: 10. 4161/auto. 25188

Celio, M. R. (1990). Calbindin D-28k and parvalbumin in the rat nervous system. Neuroscience 35, 375-475. doi: 10.1016/0306-4522(90)90091-h

Chaussenot, A., Le Ber, I., Ait-El-Mkadem, S., Camuzat, A., de Septenville, A., Bannwarth, S., et al. (2014). Screening of CHCHD10 in a French cohort confirms the involvement of this gene in frontotemporal dementia with amyotrophic lateral sclerosis patients. Neurobiol. Aging 35, 2884.e1-2884.e4. doi: 10.1016/j.neurobiolaging.2014.07.022

Chen, Y., McMillan-Ward, E., Kong, J., Israels, S. J., and Gibson, S. B. (2008). Oxidative stress induces autophagic cell death independent of apoptosis in transformed and cancer cells. Cell Death Differ. 15, 171-182. doi: 10.1038/sj. cdd. 4402233

Chen, S., Zhang, X., Song, L., and Le, W. (2012). Autophagy dysregulation in amyotrophic lateral sclerosis. Brain Pathol. 22, 110-116. doi: 10.1111/j.17503639.2011.00546.x

Chin, E. R., Chen, D., Bobyk, K. D., and Mázala, D. A. (2014). Perturbations in intracellular $\mathrm{Ca}^{2+}$ handling in skeletal muscle in the G93A*SOD1 mouse model of amyotrophic lateral sclerosis. Am. J. Physiol. Cell Physiol. 307, C1031-C1038. doi: 10.1152/ajpcell.00237.2013

Ching, J. K., Elizabeth, S. V., Ju, J. S., Lusk, C., Pittman, S. K., and Weihl, C. C. (2013). mTOR dysfunction contributes to vacuolar pathology and weakness in valosin-containing protein associated inclusion body myopathy. Hum. Mol. Genet. 22, 1167-1179. doi: 10.1093/hmg/dds524

Chistiakov, D. A., Sobenin, I. A., Revin, V. V., Orekhov, A. N., and Bobryshev, Y. V. (2014). Mitochondrial aging and age-related dysfunction of mitochondria. Biomed Res. Int. 2014:238463. doi: 10.1155/2014/ 238463

Cirulli, E. T., Lasseigne, B. N., Petrovski, S., Sapp, P. C., Dion, P. A., Leblond, C. S., et al. (2015). Exome sequencing in amyotrophic lateral sclerosis identifies risk genes and pathways. Science 347, 1436-1441. doi: 10.1126/science. aaa3650

Clark, I. E., Dodson, M. W., Jiang, C., Cao, J. H., Huh, J. R., Seol, J. H., et al. (2006). Drosophila pink1 is required for mitochondrial function and interacts genetically with parkin. Nature 441, 1162-1166. doi: 10.1038/nature 04779

Corona, J. C., and Tapia, R. (2007). $\mathrm{Ca}^{2+}$-permeable AMPA receptors and intracellular $\mathrm{Ca}^{2+}$ determine motoneuron vulnerability in rat spinal cord in vivo. Neuropharmacology 52, 1219-1228. doi: 10.1016/j.neuropharm.2006. 12.008

Cozzolino, M., and Carri, M. T. (2012). Mitochondrial dysfunction in ALS. Prog. Neurobiol. 97, 54-66. doi: 10.1016/j.pneurobio.2011.06.003

Dai, R. M., and Li, C. C. (2001). Valosin-containing protein is a multi-ubiquitin chain-targeting factor required in ubiquitin-proteasome degradation. Nat. Cell Biol. 3, 740-744. doi: 10.1038/35087056

Damiano, M., Starkov, A. A., Petri, S., Kipiani, K., Kiaei, M., Mattiazzi, M., et al. (2006). Neural mitochondrial $\mathrm{Ca}^{2+}$ capacity impairment precedes the onset of motor symptoms in G93A Cu/Zn-superoxide dismutase mutant mice. J. Neurochem. 96, 1349-1361. doi: 10.1111/j.1471-4159.2006.03619.x

Deas, E., Plun-Favreau, H., Gandhi, S., Desmond, H., Kjaer, S., Loh, S. H., et al. (2011). PINK1 cleavage at position A103 by the mitochondrial protease PARL. Hum. Mol. Genet. 20, 867-879. doi: 10.1093/hmg/ddq526

DeJesus-Hernandez, M., Mackenzie, I. R., Boeve, B. F., Boxer, A. L., Baker, M., Rutherford, N. J., et al. (2011). Expanded GGGGCC hexanucleotide repeat in noncoding region of C9ORF72 causes chromosome 9p-linked FTD and ALS. Neuron 72, 245-256. doi: 10.1016/j.neuron.2011.09.011

Deng, H. X., Bigio, E. H., Zhai, H., Fecto, F., Ajroud, K., Shi, Y., et al. (2011a). Differential involvement of optineurin in amyotrophic lateral sclerosis with or without SOD1 mutations. Arch. Neurol. 68, 1057-1061. doi: 10. 1001/archneurol.2011.178

Deng, H. X., Chen, W., Hong, S. T., Boycott, K. M., Gorrie, G. H., Siddique, N., et al. (2011b). Mutations in UBQLN2 cause dominant X-linked juvenile and adult-onset alS and ALS/dementia. Nature 477, 211-215. doi: 10. 1038/nature 10353

Deng, H. X., Shi, Y., Furukawa, Y., Zhai, H., Fu, R., Liu, E., et al. (2006). Conversion to the amyotrophic lateral sclerosis phenotype is associated with intermolecular linked insoluble aggregates of SOD1 in mitochondria. Proc. Natl. Acad. Sci. US A 103, 7142-7147. doi: 10.1073/pnas.0602046103

De Vos, K. J., Chapman, A. L., Tennant, M. E., Manser, C., Tudor, E. L., Lau, K. F., et al. (2007). Familial amyotrophic lateral sclerosis-linked SOD1 mutants perturb fast axonal transport to reduce axonal mitochondria content. Hum. Mol. Genet. 16, 2720-2728. doi: 10.1093/hmg/ddm226

De Vos, K. J., Grierson, A. J., Ackerley, S., and Miller, C. C. (2008). Role of axonal transport in neurodegenerative diseases. Annu. Rev. Neurosci. 31, 151-173. doi: 10.1146/annurev.neuro.31.061307.090711 
Egan, D. F., Shackelford, D. B., Mihaylova, M. M., Gelino, S., Kohnz, R. A., Mair, W., et al. (2011). Phosphorylation of ULK1 (hATG1) by AMP-activated protein kinase connects energy sensing to mitophagy. Science 331, 456-461. doi: 10.1126/science.1196371

Elliott, J. L., and Snider, W. D. (1995). Parvalbumin is a marker of ALS-resistant motor neurons. Neuroreport 6, 449-452. doi: 10.1097/00001756-19950200000011

Fahed, A. C., McDonough, B., Gouvion, C. M., Newell, K. L., Dure, L. S., Bebin, M., et al. (2014). UBQLN2 mutation causing heterogeneous X-linked dominant neurodegeneration. Ann. Neurol. 75, 793-798. doi: 10.1002/ana. 24164

Farg, M. A., Sundaramoorthy, V., Sultana, J. M., Yang, S., Atkinson, R. A., Levina, V., et al. (2014). C9ORF72, implicated in amytrophic lateral sclerosis and frontotemporal dementia, regulates endosomal trafficking. Hum. Mol. Genet. 23, 3579-3595. doi: 10.1093/hmg/ddu068

Fecto, F., and Siddique, T. (2012). UBQLN2/P62 cellular recycling pathways in amyotrophic lateral sclerosis and frontotemporal dementia. Muscle Nerve 45, 157-162. doi: 10.1002/mus.23278

Fecto, F., Yan, J., Vemula, S. P., Liu, E., Yang, Y., Chen, W., et al. (2011). SQSTM1 mutations in familial and sporadic amyotrophic lateral sclerosis. Arch. Neurol. 68, 1440-1446. doi: 10.1001/archneurol.2011.250

Ferri, A., Cozzolino, M., Crosio, C., Nencini, M., Casciati, A., Gralla, E. B., et al. (2006). Familial ALS-superoxide dismutases associate with mitochondria and shift their redox potentials. Proc. Natl. Acad. Sci. U S A 103, 13860-13865. doi: 10.1073/pnas.0605814103

Forman, D. S., Brown, K. J., and Promersberger, M. E. (1983). Selective inhibition of retrograde axonal transport by erythro-9-[3-(2-hydroxynonyl)]adenine. Brain Res. 272, 194-197. doi: 10.1016/0006-8993(83)90381-5

Freischmidt, A., Wieland, T., Richter, B., Ruf, W., Schaeffer, V., Müller, K., et al. (2015). Haploinsufficiency of TBK1 causes familial ALS and fronto-temporal dementia. Nat. Neurosci. 18, 631-636. doi: 10.1038/nn.4000

Fuchs, A., Kutterer, S., Mühling, T., Duda, J., Schütz, B., Liss, B., et al. (2013). Selective mitochondrial $\mathrm{Ca}^{2+}$ uptake deficit in disease endstage vulnerable motoneurons of the SOD1 $1^{\mathrm{G} 93 \mathrm{~A}}$ mouse model of amyotrophic lateral sclerosis. J. Physiol. 591, 2723-2745. doi: 10.1113/jphysiol.2012.247981

Fukai, T., and Ushio-Fukai, M. (2011). Superoxide dismutases: role in redox signaling, vascular function and diseases. Antioxid. Redox Signal. 15, 1583-1606. doi: 10.1089/ars.2011.3999

Gao, W., Shen, Z., Shang, L., and Wang, X. (2011). Upregulation of human autophagy-initiation kinase ULK1 by tumor suppressor p53 contributes to DNA-damage-induced cell death. Cell Death Differ. 18, 1598-1607. doi: 10. 1038/cdd.2011.33

Graf, M., Ecker, D., Horowski, R., Kramer, B., Riederer, P., Gerlach, M., et al. (2005). High dose vitamin E therapy in amyotrophic lateral sclerosis as add-on therapy to riluzole: results of a placebo-controlled double-blind study. J. Neural Transm. (Vienna) 112, 649-660. doi: 10.1007/s00702-0040220-1

Greene, J. C., Whitworth, A. J., Kuo, I., Andrews, L. A., Feany, M. B., and Pallanck, L. J. (2003). Mitochondrial pathology and apoptotic muscle degeneration in Drosophila parkin mutants. Proc. Natl. Acad. Sci. U S A 100, 4078-4083. doi: 10.1073/pnas.0737556100

Gurney, M. E., Cutting, F. B., Zhai, P., Doble, A., Taylor, C. P., Andrus, P. K., et al. (1996). Benefit of vitamin E, riluzole, and gabapentin in a transgenic model of familial amyotrophic lateral sclerosis. Ann. Neurol. 39, 147-157. doi: 10. 1002/ana.410390203

Hara, T., Nakamura, K., Matsui, M., Yamamoto, A., Nakahara, Y., SuzukiMigishima, R., et al. (2006). Suppression of basal autophagy in neural cells causes neurodegenerative disease in mice. Nature 441, 885-889. doi: 10 . 1038/nature04724

Hara, T., Takamura, A., Kishi, C., Iemura, S., Natsume, T., Guan, J. L., et al. (2008). FIP200, a ULK-interacting protein, is required for autophagosome formation in mammalian cells. J. Cell Biol. 181, 497-510. doi: 10.1083/jcb.200 712064

Hawley, S. A., Davison, M., Woods, A., Davies, S. P., Beri, R. K., Carling, D., et al. (1996). Characterization of the AMP-activated protein kinase kinase from rat liver and identification of threonine 172 as the major site at which it phosphorylates AMP-activated protein kinase. J. Biol. Chem. 271, 27879-27887. doi: 10.1074/jbc.271.44.27879
Heo, J. M., Ordureau, A., Paulo, J. A., Rinehart, J., and Harper, J. W. (2015). The PINK1-PARKIN Mitochondrial Ubiquitylation pathway drives a program of OPTN/NDP52 recruitment and TBK1 activation to promote Mitophagy. Mol. Cell 60, 7-20. doi: 10.1016/j.molcel.2015.08.016

Hosokawa, N., Sasaki, T., Iemura, S., Natsume, T., Hara, T., and Mizushima, N. (2009). Atg101, a novel mammalian autophagy protein interacting with Atg13. Autophagy 5, 973-979. doi: 10.4161/auto.5.7.9296

Huang, J., Lam, G. Y., and Brumell, J. H. (2011). Autophagy signaling through reactive oxygen species. Antioxid. Redox Signal. 14, 2215-2231. doi: 10. 1089/ars.2010.3554

Hung, S. Y., Huang, W. P., Liou, H. C., and Fu, W. M. (2009). Autophagy protects neuron from $\mathrm{A} \beta$-induced cytotoxicity. Autophagy 5, 502-510. doi: 10 . 4161/auto.5.4.8096

Ikawa, M., Okazawa, H., Tsujikawa, T., Matsunaga, A., Yamamura, O., Mori, T., et al. (2015). Increased oxidative stress is related to disease severity in the als motor cortex: a PET study. Neurology 84, 2033-2039. doi: 10.1212/WNL. 0000000000001588

Ince, P., Stout, N., Shaw, P., Slade, J., Hunziker, W., Heizmann, C. W., et al. (1993). Parvalbumin and calbindin D-28k in the human motor system and in motor neuron disease. Neuropathol. Appl. Neurobiol. 19, 291-299. doi: 10.1111/j.13652990.1993.tb00443.x

Jaarsma, D., Rognoni, F., van Duijn, W., Verspaget, H. W., Haasdijk, E. D., and Holstege, J. C. (2001). CuZn superoxide dismutase (SOD1) accumulates in vacuolated mitochondria in transgenic mice expressing amyotrophic lateral sclerosis-linked SOD1 mutations. Acta Neuropathol. 102, 293-305. doi: 10. 1007/s004010100399

Jaiswal, M. K., and Keller, B. U. (2009). Cu/Zn superoxide dismutase typical for familial amyotrophic lateral sclerosis increases the vulnerability of mitochondria and perturbs $\mathrm{Ca}^{2+}$ homeostasis in SOD1 ${ }^{\mathrm{G} 93 \mathrm{~A}}$ mice. Mol. Pharmacol. 75, 478-489. doi: 10.1124/mol.108.050831

Jaiswal, M. K., Zech, W. D., Goos, M., Leutbecher, C., Ferri, A., Zippelius, A., et al. (2009). Impairment of mitochondrial calcium handling in a mtSOD1 cell culture model of motoneuron disease. BMC Neurosci. 10:64. doi: 10.1186/14712202-10-64

Jang, Y. C., and Van Remmen, H. (2009). The mitochondrial theory of aging: insight from transgenic and knockout mouse models. Exp. Gerontol. 44, 256-260. doi: 10.1016/j.exger.2008.12.006

Jay, V. (2000). The legacy of Jean-Martin Charcot. Arch. Pathol. Lab. Med. 124, 10-11. doi: 10.1043/0003-9985(2000)124<0010:TLOJMC>2.0.CO;2

Jin, S. M., and Youle, R. J. (2012). PINK1- and Parkin-mediated mitophagy at a glance. J. Cell Sci. 125, 795-799. doi: 10.1242/jcs.093849

Johnson, J. O., Glynn, S. M., Gibbs, J. R., Nalls, M. A., Sabatelli, M., Restagno, G., et al. (2014). Mutations in the CHCHD10 gene are a common cause of familial amyotrophic lateral sclerosis. Brain 137:e311. doi: 10.1093/brain/awu265

Johnson, J. O., Mandrioli, J., Benatar, M., Abramzon, Y., Van Deerlin, V. M., Trojanowski, J. Q., et al. (2010). Exome sequencing reveals VCP mutations as a cause of familial ALS. Neuron 68, 857-864. doi: 10.1016/j.neuron.2010. 11.036

Johnson, B. S., McCaffery, J. M., Lindquist, S., and Gitler, A. D. (2008). A yeast TDP-43 proteinopathy model: exploring the molecular determinants of TDP43 aggregation and cellular toxicity. Proc. Natl. Acad. Sci. US A 105, 6439-6444. doi: 10.1073/pnas.0802082105

Johnson, B. S., Snead, D., Lee, J. J., McCaffery, J. M., Shorter, J., and Gitler, A. D. (2009). TDP-43 is intrinsically aggregation-prone and amyotrophic lateral sclerosis-linked mutations accelerate aggregation and increase toxicity. J. Biol. Chem. 284, 20329-20339. doi: 10.1074/jbc.M109.010264

Joshi, A., Iyengar, R., Joo, J. H., Li-Harms, X. J., Wright, C., Marino, R., et al. (2016). Nuclear ULK1 promotes cell death in response to oxidative stress through PARP1. Cell Death Differ. 23, 216-230. doi: 10.1038/cdd. 2015.88

Ju, J. S., Fuentealba, R. A., Miller, S. E., Jackson, E., Piwnica-Worms, D., Baloh, R. H., et al. (2009). Valosin-containing protein (VCP) is required for autophagy and is disrupted in VCP disease. J. Cell Biol. 187, 875-888. doi: 10. 1083/jcb.200908115

Jung, C., Higgins, C. M., and Xu, Z. (2002). Mitochondrial electron transport chain complex dysfunction in a transgenic mouse model for amyotrophic lateral sclerosis. J. Neurochem. 83, 535-545. doi: 10.1046/j.1471-4159.2002. 01112.x 
Jung, C. H., Jun, C. B., Ro, S. H., Kim, Y. M., Otto, N. M., Cao, J., et al. (2009). ULK-Atg13-FIP200 complexes mediate mTOR signaling to the autophagy machinery. Mol. Biol. Cell 20, 1992-2003. doi: 10.1091/mbc.E08-12-1249

Kabashi, E., Valdmanis, P. N., Dion, P., Spiegelman, D., McConkey, B. J., Vande Velde, C., et al. (2008). TARDBP mutations in individuals with sporadic and familial amyotrophic lateral sclerosis. Nat. Genet. 40, 572-574. doi: 10.1038/ ng.132

Kang, J. S., Tian, J. H., Pan, P. Y., Zald, P., Li, C., Deng, C., et al. (2008). Docking of axonal mitochondria by syntaphilin controls their mobility and affects shortterm facilitation. Cell 132, 137-148. doi: 10.1016/j.cell.2007.11.024

Khandelwal, P. J., Herman, A. M., Hoe, H. S., Rebeck, G. W., and Moussa, C. E. (2011). Parkin mediates beclin-dependent autophagic clearance of defective mitochondria and ubiquitinated $\mathrm{A} \beta$ in $\mathrm{AD}$ models. Hum. Mol. Genet. 20, 2091-2102. doi: 10.1093/hmg/ddr091

Kim, J., Kundu, M., Viollet, B., and Guan, K. L. (2011). AMPK and mTOR regulate autophagy through direct phosphorylation of Ulk1. Nat. Cell Biol. 13, 132-141. doi: $10.1038 /$ ncb2152

Kim, I., Rodriguez-Enriquez, S., and Lemasters, J. J. (2007). Selective degradation of mitochondria by mitophagy. Arch. Biochem. Biophys. 462, 245-253. doi: 10. 1016/j.abb.2007.03.034

Kim, N. C., Tresse, E., Kolaitis, R. M., Molliex, A., Thomas, R. E., Alami, N. H., et al. (2013). VCP is essential for mitochondrial quality control by PINK1/Parkin and this function is impaired by VCP mutations. Neuron 78, 65-80. doi: 10 . 1016/j.neuron.2013.02.029

Kirk, K., Gennings, C., Hupf, J. C., Tadesse, S., D’Aurelio, M., Kawamata, H., et al. (2014). Bioenergetic markers in skin fibroblasts of sporadic amyotrophic lateral sclerosis and progressive lateral sclerosis patients. Ann. Neurol. 76, 620-624. doi: 10.1002/ana.24244

Kitamura, A., Inada, N., Kubota, H., Matsumoto, G., Kinjo, M., Morimoto, R. I., et al. (2014). Dysregulation of the proteasome increases the toxicity of ALS-linked mutant SOD1. Genes Cells 19, 209-224. doi: 10.1111/gtc. 12125

Klionsky, D. J., Cregg, J. M., Dunn, W. A., Jr., Emr, S. D., Sakai, Y., Sandoval, I. V., et al. (2003). A unified nomenclature for yeast autophagy-related genes. Dev. Cell 5, 539-545. doi: 10.1016/s1534-5807(03)00296-x

Koike, M., Shibata, M., Tadakoshi, M., Gotoh, K., Komatsu, M., Waguri, S., et al. (2008). Inhibition of autophagy prevents hippocampal pyramidal neuron death after hypoxic-ischemic injury. Am. J. Pathol. 172, 454-469. doi: 10.2353/ajpath. 2008.070876

Komatsu, M., Waguri, S., Chiba, T., Murata, S., Iwata, J., Tanida, I., et al. (2006). Loss of autophagy in the central nervous system causes neurodegeneration in mice. Nature 441, 880-884. doi: 10.1038/nature04723

Koppers, M., van Blitterswijk, M. M., Vlam, L., Rowicka, P. A., van Vught, P. W., Groen, E. J., et al. (2012). VCP mutations in familial and sporadic amyotrophic lateral sclerosis. Neurobiol. Aging 33, 837e.7-837.e13. doi: 10 . 1016/j.neurobiolaging.2011.10.006

Koyano, F., Okatsu, K., Kosako, H., Tamura, Y., Go, E., Kimura, M., et al. (2014). Ubiquitin is phosphorylated by PINK1 to activate parkin. Nature 510, 162-166. doi: 10.1038/nature13392

Kühnlein, P., Sperfeld, A. D., Vanmassenhove, B., Van Deerlin, V., Lee, V. M., Trojanowski, J. Q., et al. (2008). Two German kindreds with familial amyotrophic lateral sclerosis due to TARDBP mutations. Arch. Neurol. 65, 1185-1189. doi: 10.1001/archneur.65.9.1185

Lacomblez, L., Bensimon, G., Leigh, P. N., Guillet, P., and Meininger, V. (1996). Dose-ranging study of riluzole in amyotrophic lateral sclerosis. Amyotrophic lateral Sclerosis/Riluzole study group II. Lancet 347, 1425-1431. doi: 10. 1016/s0140-6736(96)91680-3

Lazarou, M., Sliter, D. A., Kane, L. A., Sarraf, S. A., Wang, C., Burman, J. L., et al. (2015). The ubiquitin kinase PINK1 recruits autophagy receptors to induce mitophagy. Nature 524, 309-314. doi: 10.1038/nature14893

Le Masson, G., Przedborski, S., and Abbott, L. F. (2014). A computational model of motor neuron degeneration. Neuron 83, 975-988. doi: 10.1016/j.neuron.2014. 07.001

Li, L., Chen, Y., and Gibson, S. B. (2013). Starvation-induced autophagy is regulated by mitochondrial reactive oxygen species leading to AMPK activation. Cell. Signal. 25, 50-65. doi: 10.1016/j.cellsig.2012.09.020

Ligon, L. A., LaMonte, B. H., Wallace, K. E., Weber, N., Kalb, R. G., and Holzbaur, E. L. (2005). Mutant superoxide dismutase disrupts cytoplasmic dynein in motor neurons. Neuroreport 16, 533-536. doi: 10.1097/00001756200504250-00002

Ling, S. C., Polymenidou, M., and Cleveland, D. W. (2013). Converging mechanisms in ALS and FTD: disrupted RNA and protein homeostasis. Neuron 79, 416-438. doi: 10.1016/j.neuron.2013.07.033

Lim, J., and Yue, Z. (2015). Neuronal aggregates: formation, clearance, and spreading. Dev. Cell 32, 491-501. doi: 10.1016/j.devcel.2015.02.002

Linkermann, A., and Green, D. R. (2014). Necroptosis. N. Engl. J. Med. 370, 455-465. doi: 10.1056/NEJMra1310050

Lips, M. B., and Keller, B. U. (1998). Endogenous calcium buffering in motoneurones of the nucleus hypoglossus from mouse. J. Physiol. 511, 105-117. doi: 10.1111/j.1469-7793.1998.105bi.x

Liu, L., Feng, D., Chen, G., Chen, M., Zheng, Q., Song, P., et al. (2012). Mitochondrial outer-membrane protein FUNDC1 mediates hypoxia-induced mitophagy in mammalian cells. Nat. Cell Biol. 14, 177-185. doi: 10 $1038 /$ ncb 2422

Liu, Y., and Levine, B. (2015). Autosis and autophagic cell death: the dark side of autophagy. Cell Death Differ. 22, 367-376. doi: 10.1038/cdd. 2014.143

Liu, J., Lillo, C., Jonsson, P. A., Vande Velde, C., Ward, C. M., Miller, T. M., et al. (2004). Toxicity of familial ALS-linked SOD1 mutants from selective recruitment to spinal mitochondria. Neuron 43, 5-17. doi: 10.1016/j.neuron. 2004.06.016

Liu, Y., Shoji-Kawata, S., Sumpter, R. M., Jr., Wei, Y., Ginet, V., Zhang, L., et al. (2013). Autosis is a $\mathrm{Na}^{+}, \mathrm{K}^{+}$-ATPase-regulated form of cell death triggered by autophagy-inducing peptides, starvation and hypoxia-ischemia. Proc. Natl. Acad. Sci. U S A 110, 20364-20371. doi: 10.1073/pnas.13196 61110

Lonskaya, I., Hebron, M. L., Desforges, N. M., Franjie, A., and Moussa, C. E. (2013). Tyrosine kinase inhibition increases functional parkin-Beclin-1 interaction and enhances amyloid clearance and cognitive performance. EMBO Mol. Med. 5, 1247-1262. doi: 10.1002/emmm.201302771

Luo, C., Li, Y., Wang, H., Feng, Z., Li, Y., Long, J., et al. (2013). Mitochondrial accumulation under oxidative stress is due to defects in autophagy. J. Cell. Biochem. 114, 212-219. doi: 10.1002/jcb.24356

Mackenzie, I. R., Bigio, E. H., Ince, P. G., Geser, F., Neumann, M., Cairns, N. J., et al. (2007). Pathological TDP-43 distinguishes sporadic amyotrophic lateral sclerosis from amyotrophic lateral sclerosis with SOD1 mutations. Ann. Neurol. 61, 427-434. doi: 10.1002/ana.21147

Magrané, J., Cortez, C., Gan, W. B., and Manfredi, G. (2014). Abnormal mitochondrial transport and morphology are common pathological denominators in SOD1 and TDP43 ALS mouse models. Hum. Mol. Genet. 23, 1413-1424. doi: 10.1093/hmg/ddt528

Magrané, J., Sahawneh, M. A., Przedborski, S., Estévez, A. G., and Manfredi, G. (2012). Mitochondrial dynamics and bioenergetic dysfunction is associated with synaptic alterations in mutant SOD1 motor neurons. J. Neurosci. 32, 229-242. doi: 10.1523/JNEUROSCI.1233-11.2012

Marinkovic, P., Reuter, M. S., Brill, M. S., Godinho, L., Kerschensteiner, M., and Misgeld, T. (2012). Axonal transport deficits and degeneration can evolve independently in mouse models of amyotrophic lateral sclerosis. Proc. Natl. Acad. Sci. U S A 109, 4296-4301. doi: 10.1073/pnas.1200 658109

Maruyama, H., Morino, H., Ito, H., Izumi, Y., Kato, H., Watanabe, Y., et al. (2010). Mutations of optineurin in amyotrophic lateral sclerosis. Nature 465, 223-226. doi: $10.1038 /$ nature 08971

Milstein, J. M., and Swaiman, K. F. (1968). The influence of electron transport chain inhibitors on mature rate brain mitochondria. Neurology 18, 297-298.

Mironov, S. L. (2007). ADP regulates movements of mitochondria in neurons. Biophys. J. 92, 2944-2952. doi: 10.1529/biophysj.106.092981

Mizuno, Y., Amari, M., Takatama, M., Aizawa, H., Mihara, B., and Okamoto, K. (2006). Immunoreactivities of p62, an ubiqutin-binding protein, in the spinal anterior horn cells of patients with amyotrophic lateral sclerosis. J. Neurol. Sci. 249, 13-18. doi: 10.1016/j.jns.2006.05.060

Mizushima, N. (2007). Autophagy: process and function. Genes Dev. 21, 2861-2873. doi: 10.1101/gad.1599207

Mizushima, N. (2010). The role of the Atg1/ULK1 complex in autophagy regulation. Curr. Opin. Cell Biol. 22, 132-139. doi: 10.1016/j.ceb.2009.12.004 
Mizushima, N., Yoshimori, T., and Ohsumi, Y. (2011). The role of Atg proteins in autophagosome formation. Annu. Rev. Cell Dev. Biol. 27, 107-132. doi: 10. 1146/annurev-cellbio-092910-154005

Münch, C., Rosenbohm, A., Sperfeld, A. D., Uttner, I., Reske, S., Krause, B. J., et al. (2005). Heterozygous R1101K mutation of the DCTN1 gene in a family with ALS and FTD. Ann. Neurol. 58, 777-780. doi: 10.1002/ana.20631

Münch, C., Sedlmeier, R., Meyer, T., Homberg, V., Sperfeld, A. D., Kurt, A., et al. (2004). Point mutations of the p150 subunit of dynactin (DCTN1) gene in ALS. Neurology 63, 724-726. doi: 10.1212/01.wnl.0000134608.83927.b1

Narendra, D. P., Jin, S. M., Tanaka, A., Suen, D. F., Gautier, C. A., Shen, J., et al. (2010). PINK1 is selectively stabilized on impaired mitochondria to activate Parkin. PLoS Biol. 8:e1000298. doi: 10.1371/journal.pbio.1000298

N’Diaye, E. N., Kajihara, K. K., Hsieh, I., Morisaki, H., Debnath, J., and Brown, E. J. (2009). PLIC proteins or ubiquilins regulate autophagy-dependent cell survival during nutrient starvation. EMBO Rep. 10, 173-179. doi: 10.1038/embor. 2008.238

Neumann, M., Sampathu, D. M., Kwong, L. K., Truax, A. C., Micsenyi, M. C., Chou, T. T., et al. (2006). Ubiquitinated TDP-43 in frontotemporal lobar degeneration and amyotrophic lateral sclerosis. Science 314, 130-133. doi: 10. $1126 /$ science. 1134108

Nguyen, K. T., García-Chacon, L. E., Barrett, J. N., Barrett, E. F., and David, G. (2009). The Psi(m) depolarization that accompanies mitochondrial $\mathrm{Ca}^{2+}$ uptake is greater in mutant SOD1 than in wild-type mouse motor terminals. Proc. Natl. Acad. Sci. U S A 106, 2007-2011. doi: 10.1073/pnas.0810934106

Nguyen, T. T., Oh, S. S., Weaver, D., Lewandowska, A., Maxfield, D., Schuler, M. H., et al. (2014). Loss of Miro1-directed mitochondrial movement results in a novel murine model for neuron disease. Proc. Natl. Acad. Sci. U S A 111, E3631-E3640. doi: 10.1073/pnas.1402449111

Nishimura, A. L., Mitne-Neto, M., Silva, H. C., Oliveira, J. R., Vainzof, M., and Zatz, M. (2004a). A novel locus for late onset amyotrophic lateral sclerosis/motor neurone disease variant at 20q13. J. Med. Genet. 41, 315-320. doi: $10.1136 / \mathrm{jmg} .2003 .013029$

Nishimura, A. L., Mitne-Neto, M., Silva, H. C., Richieri-Costa, A., Middleton, S., Cascio, D., et al. (2004b). A mutation in the vesicle-trafficking protein VAPB causes late-onset spinal muscular atrophy and amyotrophic lateral sclerosis. Am. J. Hum. Genet. 75, 822-831. doi: 10.1086/425287

Obara, K., and Ohsumi, Y. (2011). PtdIns 3-kinase Orchestrates Autophagosome formation in yeast. J. Lipids 2011:498768. doi: 10.1155/2011/498768

Orrell, R. W., Lane, R. J., and Ross, M. (2008). A systematic review of antioxidant treatment for amyotrophic lateral sclerosis/motor neuron disease. Amyotroph. Lateral Scler. 9, 195-211. doi: 10.1080/17482960801900032

Palecek, J., Lips, M. B., and Keller, B. U. (1999). Calcium dynamics and buffering in motoneurones of the mouse spinal cord. J. Physiol. 520, 485-502. doi: 10. 1111/j.1469-7793.1999.00485.x

Pankiv, S., Clausen, T. H., Lamark, T., Brech, A., Bruun, J. A., Øutzen, H., et al. (2007). p62/SQSTM1 binds directly to Atg8/LC3 to facilitate degradation of ubiquitinated protein aggregates by autophagy. J. Biol. Chem. 282, 24131-24145. doi: 10.1074/jbc.m702824200

Parone, P. A., Da Cruz, S., Han, J. S., McAlonis-Downes, M., Vetto, A. P., Lee, S. K., et al. (2013). Enhancing mitochondrial calcium buffering capacity reduces aggregation of misfolded SOD1 and motor neuron cell death without extending survival in mouse models of inherited amyotrophic lateral sclerosis. J. Neurosci. 33, 4657-4671. doi: 10.1523/JNEUROSCI.1119-12.2013

Pesah, Y., Pham, T., Burgess, H., Middlebrooks, B., Verstreken, P., Zhou, Y., et al. (2004). Drosophila parkin mutants have decreased mass and cell size and increased sensitivity to oxygen radical stress. Development 131, 2183-2194. doi: 10.1242/dev.01095

Petri, S., Kiaei, M., Damiano, M., Hiller, A., Wille, E., Manfredi, G., et al. (2006). Cell-permeable peptide antioxidants as a novel therapeutic approach in a mouse model of amyotrophic lateral sclerosis. J. Neurochem. 98, 1141-1148. doi: 10.1111/j.1471-4159.2006.04018.x

Plowey, E. D., Cherra, S. J., III, Liu, Y. J., and Chu, C. T. (2008). Role of autophagy in G2019S-LRRK2-associated neurite shortening in differentiated SH-SY5Y cells. J. Neurochem. 105, 1048-1056. doi: 10.1111/j.1471-4159.2008. 05217.x

Polymenidou, M., and Cleveland, D. W. (2012). Prion-like spread of protein aggregates in neurodegeneration. J. Exp. Med. 209, 889-893. doi: 10.1084/jem. 20120741
Poole, A. C., Thomas, R. E., Andrews, L. A., McBride, H. M., Whitworth, A. J., and Pallanck, L. J. (2008). The PINK1/Parkin pathway regulates mitochondrial morphology. Proc. Natl. Acad. Sci. U S A 105, 1638-1643. doi: 10.1073/pnas. 0709336105

Poole, A. C., Thomas, R. E., Yu, S., Vincow, E. S., and Pallanck, L. (2010). The mitochondrial fusion-promoting factor mitofusin is a substrate of the PINK1/parkin pathway. PLoS One 5:e10054. doi: 10.1371/journal.pone. 0010054

Rabinovich, E., Kerem, A., Frohlich, K. U., Diamant, N., and Bar-Nun, S. (2002). AAA-ATPase p97/Cdc48p, a cytosolic chaperone required for endoplasmic reticulum-associated protein degradation. Mol. Cell. Biol. 22, 626-634. doi: 10. $1128 / \mathrm{mcb} .22 .2 .626-634.2002$

Re, D. B., Le Verche, V., Yu, C., Amoroso, M. W., Politi, K. A., Phani, S., et al. (2014). Necroptosis drives motor neuron death in models of both sporadic and familial ALS. Neuron 81, 1001-1008. doi: 10.1016/j.neuron.2014.01.011

Renton, A. E., Majounie, E., Waite, A., Simón-Sánchez, J., Rollinson, S., Gibbs, J. R., et al. (2011). A hexanucleotide repeat expansion in C9ORF72 is the cause of chromosome 9p21-linked ALS-FTD. Neuron 72, 257-268. doi: 10. 1016/j.neuron.2011.09.010

Rintoul, G. L., Filiano, A. J., Brocard, J. B., Kress, G. J., and Reynolds, I. J. (2003). Glutamate decreases mitochondrial size and movement in primary forebrain neurons. J. Neurosci. 23, 7881-7888.

Rojas, F., Gonzalez, D., Cortes, N., Ampuero, E., Hernandez, D. E., Fritz, E., et al. (2015). Reactive oxygen species trigger motoneuron death in non-cellautonomous models of ALS through activation of c-Abl signaling. Front. Cell. Neurosci. 9:203. doi: 10.3389/fncel.2015.00203

Romanov, J., Walczak, M., Ibiricu, I., Schüchner, S., Ogris, E., Kraft, C., et al. (2012). Mechanism and functions of membrane binding by the Atg5-Atg12/Atg16 complex during autophagosome formation. EMBO J. 31, 4304-4317. doi: 10.1038/emboj.2012.278

Rosen, D. R. (1993). Mutations in $\mathrm{Cu} / \mathrm{Zn}$ superoxide dismutase gene are associated with familial amyotrophic lateral sclerosis. Nature 364:362. doi: 10 . $1038 / 364362 \mathrm{c} 0$

Rosen, D. R., Siddique, T., Patterson, D., Figlewicz, D. A., Sapp, P., Hentati, A., et al. (1993). Mutations in $\mathrm{Cu} / \mathrm{Zn}$ superoxide dismutase gene are associated with familial amyotrophic lateral sclerosis. Nature 362, 59-62. doi: 10. 1038/362059a0

Rothenberg, C., Srinivasan, D., Mah, L., Kaushik, S., Peterhoff, C. M., Ugolino, J., et al. (2010). Ubiquilin functions in autophagy and is degraded by chaperone-mediated autophagy. Hum. Mol. Genet. 19, 3219-3232. doi: 10. 1093/hmg/ddq231

Rotunno, M. S., and Bosco, D. A. (2013). An emerging role for misfolded wildtype SOD1 in sporadic ALS pathogenesis. Front. Cell. Neurosci. 7:253. doi: 10. 3389/fncel.2013.00253

Rowland, L. P., and Shneider, N. A. (2001). Amyotrophic lateral sclerosis. N. Engl. J. Med. 344, 1688-1700. doi: 10.1056/NEJM200105313442207

Russell, R. C., Tian, Y., Yuan, H., Park, H. W., Chang, Y. Y., Kim, J., et al. (2013). ULK1 induces autophagy by phosphorylating Beclin-1 and activating VPS34 lipid kinase. Nat. Cell Biol. 15, 741-750. doi: 10.1038/ncb2757

Ryter, S. W., Cloonan, S. M., and Choi, A. M. (2013). Autophagy: a critical regulator of cellular metabolism and homeostasis. Mol. Cells 36, 7-16. doi: 10. 1007/s10059-013-0140-8

Ryter, S. W., Kim, H. P., Hoetzel, A., Park, J. W., Nakahira, K., Wang, X., et al. (2007). Mechanisms of cell death in oxidative stress. Antioxid. Redox Signal. 9, 49-89. doi: 10.1089/ars.2007.9.49

Sau, D., De Biasi, S., Vitellaro-Zuccarello, L., Riso, P., Guarnieri, S., Porrini, M., et al. (2007). Mutation of SOD1 in ALS: a gain of a loss of function. Hum. Mol. Genet. 16, 1604-1618. doi: 10.1093/hmg/ddm110

Scherz-Shouval, R., and Elazar, Z. (2011). Regulation of autophagy by ROS: physiology and pathology. Trends Biochem. Sci. 36, 30-38. doi: 10.1016/j.tibs. 2010.07.007

Scherz-Shouval, R., Shvets, E., Fass, E., Shorer, H., Gil, L., and Elazar, Z. (2007). Reactive oxygen species are essential for autophagy and specifically regulate the activity of Atg4. EMBO J. 26, 1749-1760. doi: 10.1038/sj.emboj.7601623

Seibenhener, M. L., Babu, J. R., Geetha, T., Wong, H. C., Krishna, N. R., and Wooten, M. W. (2004). Sequestosome 1/p62 is a polyubiquitin chain binding protein involved in ubiquitin proteasome degradation. Mol. Cell. Biol. 24, 8055-8068. doi: 10.1128/mcb.24.18.8055-8068.2004 
Shan, X., Chiang, P. M., Price, D. L., and Wong, P. C. (2010). Altered distributions of Gemini of coiled bodies and mitochondria in motor neurons of TDP43 transgenic mice. Proc. Natl. Acad. Sci. U S A 107, 16325-16330. doi: 10. 1073/pnas.1003459107

Sheng, Z. H. (2014). Mitochondrial trafficking and anchoring in neurons: new insight and implications. J. Cell Biol. 204, 1087-1098. doi: 10.1083/jcb. 201312123

Shiba-Fukushima, K., Imai, Y., Yoshida, S., Ishihama, Y., Kanao, T., Sato, S., et al. (2012). PINK1-mediated phosphorylation of the Parkin ubiquitin-like domain primes mitochondrial translocation of Parkin and regulates mitophagy. Sci. Rep. 2:1002. doi: 10.1038/srep01002

Siklós, L., Engelhardt, J., Harati, Y., Smith, R. G., Joo, F., and Appel, S. H. (1996). Ultrastructural evidence for altered calcium in motor nerve terminals in amyotropic lateral sclerosis. Ann. Neurol. 39, 203-216. doi: 10.1002/ana. 410390210

Singh, R., and Cuervo, A. M. (2011). Autophagy in the cellular energetic balance. Cell Metab. 13, 495-504. doi: 10.1016/j.cmet.2011.04.004

Staats, K. A., Hernandez, S., Schönefeldt, S., Bento-Abreu, A., Dooley, J., Van Damme, P., et al. (2013). Rapamycin increases survival in ALS mice lacking mature lymphocytes. Mol. Neurodegener. 8:31. doi: 10.1186/1750-1326-8-31

Stowers, R. S., Megeath, L. J., Górska-Andrzejak, J., Meinertzhagen, I. A., and Schwarz, T. L. (2002). Axonal transport of mitochondria to synapses depends on milton, a novel Drosophila protein. Neuron 36, 1063-1077. doi: 10. 1016/s0896-6273(02)01094-2

Strappazzon, F., Nazio, F., Corrado, M., Cianfanelli, V., Romagnoli, A., Fimia, G. M., et al. (2015). AMBRA1 is able to induce mitophagy via LC3 binding, regardless of PARKIN and p62/SQSTM1. Cell Death Differ. 22, 419-432. doi: 10.1038/cdd.2014.139

Szabadkai, G., Simoni, A. M., Bianchi, K., De Stefani, D., Leo, S., Wieckowski, M. R., et al. (2006). Mitochondrial dynamics and $\mathrm{Ca}^{2+}$ signaling. Biochim. Biophys. Acta 1763, 442-449. doi: 10.1016/j.bbamcr.2006.04.002

Szeto, H. H. (2006). Mitochondria-targeted peptide antioxidants: novel neuroprotective agents. AAPS J. 8, E521-E531. doi: 10.1208/aapsj080362

Tan, C. F., Eguchi, H., Tagawa, A., Onodera, O., Iwasaki, T., Tsujino, A., et al. (2007). TDP-43 immunoreactivity in neuronal inclusions in familial amyotrophic lateral sclerosis with or without SOD1 gene mutation. Acta Neuropathol. 113, 535-542. doi: 10.1007/s00401-007-0206-9

Teyssou, E., Takeda, T., Lebon, V., Boillée, S., Doukouré, B., Bataillon, G., et al. (2013). Mutations in SQSTM1 encoding p62 in amyotrophic lateral sclerosis: genetics and neuropathology. Acta Neuropathol. 125, 511-522. doi: 10.1007/s00401-013-1090-0

Tradewell, M. L., Cooper, L. A., Minotti, S., and Durham, H. D. (2011). Calcium dysregulation, mitochondrial pathology and protein aggregation in a culture model of amyotrophic lateral sclerosis: mechanistic relationship and differential sensitivity to intervention. Neurobiol. Dis. 42, 265-275. doi: 10. 1016/j.nbd.2011.01.016

Turturro, S., Shen, X., Shyam, R., Yue, B. Y., and Ying, H. (2014). Effects of mutations and deletions in the human optineurin gene. Springerplus 3:99. doi: 10.1186/2193-1801-3-99

Van Damme, P., Van Den Bosch, L., Van Houtte, E., Callewaert, G., and Robberecht, W. (2002). GluR2-dependent properties of AMPA receptors determine the selective vulnerability of motor neurons to excitotoxicity. J. Neurophysiol. 88, 1279-1287.

Vanden Berghe, T., Linkermann, A., Jouan-Lanhouet, S., Walczak, H., and Vandenabeele, P. (2014). Regulated necrosis: the expanding network of nonapoptotic cell death pathways. Nat. Rev. Mol. Cell Biol. 15, 135-147. doi: 10. 1038/nrm3737

Van Den Bosch, L., Van Damme, P., Bogaert, E., and Robberecht, W. (2006). The role of excitotoxicity in the pathogenesis of amyotrophic lateral sclerosis. Biochim. Biophys. Acta 1762, 1068-1082. doi: 10.1016/j.bbadis.2006. 05.002

Van Humbeeck, C., Cornelissen, T., and Vandenberghe, W. (2011). Ambra1: a Parkin-binding protein involved in mitophagy. Autophagy 7, 1555-1556. doi: 10.4161/auto.7.12.17893

Vanselow, B. K., and Keller, B. U. (2000). Calcium dynamics and buffering in oculomotor neurones from mouse that are particularly resistant during amyotrophic lateral sclerosis (ALS)-related motoneurone disease. J. Physiol. 525, 433-445. doi: 10.1111/j.1469-7793.2000.t01-1-00433.x
Vidal, R. L., Matus, S., Bargsted, L., and Hetz, C. (2014). Targeting autophagy in neurodegenerative diseases. Trends Pharmacol. Sci. 35, 583-591. doi: 10.1016/j. tips.2014.09.002

Vives-Bauza, C., Zhou, C., Huang, Y., Cui, M., de Vries, R. L., Kim, J., et al. (2010). PINK1-dependent recruitment of Parkin to mitochondria in mitophagy. Proc. Natl. Acad. Sci. U S A 107, 378-383. doi: 10.1073/pnas.0911187107

Volinia, S., Dhand, R., Vanhaesebroeck, B., MacDougall, L. K., Stein, R., Zvelebil, M. J., et al. (1995). A human phosphatidylinositol 3-kinase complex related to the yeast Vps34p-Vps15p protein sorting system. EMBO J. 14 , 3339-3348.

Volkening, K., Leystra-Lantz, C., Yang, W., Jaffee, H., and Strong, M. J. (2009). Tar DNA binding protein of $43 \mathrm{kDa}$ (TDP-43), 14-3-3 proteins and copper/zinc superoxide dismutase (SOD1) interact to modulate NFL mRNA stability. Implications for altered RNA processing in amyotrophic lateral sclerosis (ALS). Brain Res. 1305, 168-182. doi: 10.1016/j.brainres.2009. 09.105

Volonte, C., Apolloni, S., and Parisi, C. (2015). MicroRNAs: newcomers into the ALS picture. CNS Neurol. Disord. Drug Targets 14, 194-207. doi: 10. 2174/1871527314666150116125506

von Lewinski, F., Fuchs, J., Vanselow, B. K., and Keller, B. U. (2008). Low Ca ${ }^{2+}$ buffering in hypoglossal motoneurons of mutant SOD1 (G93A) mice. Neurosci. Lett. 445, 224-228. doi: 10.1016/j.neulet.2008.08.084

Wang, Q. J., Ding, Y., Kohtz, D. S., Mizushima, N., Cristea, I. M., Rout, M. P., et al. (2006). Induction of autophagy in axonal dystrophy and degeneration. J. Neurosci. 26, 8057-8068. doi: 10.1523/JNEUROSCI.2261-06.2006

Wang, I. F., Guo, B. S., Liu, Y. C., Wu, C. C., Yang, C. H., Tsai, K. J., et al. (2012). Autophagy activators rescue and alleviate pathogenesis of a mouse model with proteinopathies of the TAR DNA-binding protein 43. Proc. Natl. Acad. Sci. US A 109, 15024-15029. doi: 10.1073/pnas.1206362109

Wang, D., and Hiesinger, P. R. (2012). Autophagy, neuron-specific degradation and neurodegeneration. Autophagy 8, 711-713. doi: 10.4161/auto.19660

Wang, X., and Michaelis, E. K. (2010). Selective neuronal vulnerability to oxidative stress in the brain. Front. Aging Neurosci. 2:12. doi: 10.3389/fnagi.2010.00012

Wang, H., O’Reilly, E. J., Weisskopf, M. G., Logroscino, G., McCullough, M. L., Schatzkin, A., et al. (2011). Vitamin E intake and risk of amyotrophic lateral sclerosis: a pooled analysis of data from 5 prospective cohort studies. Am. J. Epidemiol. 173, 595-602. doi: 10.1093/aje/kwq416

Wang, X., and Schwarz, T. L. (2009). The mechanism of $\mathrm{Ca}^{2+}$-dependent regulation of kinesin-mediated mitochondrial motility. Cell 136, 163-174. doi: 10.1016/j.cell.2008.11.046

Wang, I. F., Wu, L. S., Chang, H. Y., and Shen, C. K. (2008). TDP-43, the signature protein of FTLD-U, is a neuronal activity-responsive factor. J. Neurochem. 105, 797-806. doi: 10.1111/j.1471-4159.2007.05190.x

Waterman-Storer, C. M., Karki, S. B., Kuznetsov, S. A., Tabb, J. S., Weiss, D. G., Langford, G. M., et al. (1997). The interaction between cytoplasmic dynein and dynactin is required for fast axonal transport. Proc. Natl. Acad. Sci. U S A 94, 12180-12185. doi: 10.1073/pnas.94.22.12180

Wauer, T., Simicek, M., Schubert, A., and Komander, D. (2015). Mechanism of phospho-ubiquitin-induced PARKIN activation. Nature 524, 370-374. doi: 10. 1038/nature14879

Weiduschat, N., Mao, X., Hupf, J., Armstrong, N., Kang, G., Lange, D. J., et al. (2014). Motor cortex glutathione deficit in ALS measured in vivo with the J-editing technique. Neurosci. Lett. 570, 102-107. doi: 10.1016/j.neulet.2014. 04.020

Wiedemann, F. R., Manfredi, G., Mawrin, C., Beal, M. F., and Schon, E. A. (2002). Mitochondrial DNA and respiratory chain function in spinal cords of ALS patients. J. Neurochem. 80, 616-625. doi: 10.1046/j.0022-3042.2001. 00731.x

Wirawan, E., Vande Walle, L., Kersse, K., Cornelis, S., Claerhout, S., Vanoverberghe, I., et al. (2010). Caspase-mediated cleavage of Beclin-1 inactivates Beclin-1-induced autophagy and enhances apoptosis by promoting the release of proapoptotic factors from mitochondria. Cell Death Dis. 1:e18. doi: 10.1038/cddis.2009.16

Wojcik, C., Rowicka, M., Kudlicki, A., Nowis, D., McConnell, E., Kujawa, M., et al. (2006). Valosin-containing protein (p97) is a regulator of endoplasmic reticulum stress and of the degradation of $\mathrm{N}$-end rule and ubiquitin-fusion degradation pathway substrates in mammalian cells. Mol. Biol. Cell 17, 4606-4618. doi: 10.1091/mbc.e06-05-0432 
Wong, Y. C., and Holzbaur, E. L. (2014). Optineurin is an autophagy receptor for damaged mitochondria in parkin-mediated mitophagy that is disrupted by an ALS-linked mutation. Proc. Natl. Acad. Sci. U S A 111, E4439-E4448. doi: 10. 1073/pnas.1405752111

Wu, Q., Liu, M., Huang, C., Liu, X., Huang, B., Li, N., et al. (2014). Pathogenic Ubqln2 gains toxic properties to induce neuron death. Acta Neuropathol. 129, 417-428. doi: 10.1007/s00401-014-1367-y

Xie, Y., Zhou, B., Lin, M. Y., Wang, S., Foust, K. D., and Sheng, Z. H. (2015). Endolysosomal deficits augment mitochondria pathology in spinal motor neurons of asymptomatic fALS mice. Neuron 87, 355-370. doi: 10.1016/j. neuron.2015.06.026

Xu, Z., Poidevin, M., Li, X., Li, Y., Shu, L., Nelson, D. L., et al. (2013). Expanded GGGGCC repeat RNA associated with amyotrophic lateral sclerosis and frontotemporal dementia causes neurodegeneration. Proc. Natl. Acad. Sci. U S A 110, 7778-7783. doi: 10.1073/pnas.1219643110

Yang, Y., Coleman, M., Zhang, L., Zheng, X., and Yue, Z. (2013). Autophagy in axonal and dendritic degeneration. Trends Neurosci. 36, 418-428. doi: 10. 1016/j.tins.2013.04.001

Yousefi, S., Perozzo, R., Schmid, I., Ziemiecki, A., Schaffner, T., Scapozza, L., et al. (2006). Calpain-mediated cleavage of Atg5 switches autophagy to apoptosis. Nat. Cell Biol. 8, 1124-1132. doi: 10.1038/ncb1482

Zhang, D., Iyer, L. M., He, F., and Aravind, L. (2012). Discovery of novel DENN proteins: implications for the evolution of Eukaryotic intracellular membrane structures and human disease. Front. Genet. 3:283. doi: 10.3389/fgene.2012. 00283

Zhang, X., Li, L., Chen, S., Yang, D., Wang, Y., Zhang, X., et al. (2011). Rapamycin treatment augments motor neuron degeneration in SOD1 ${ }^{G 93 A}$ mouse model of amyotrophic lateral sclerosis. Autophagy 7, 412-425. doi: 10.4161/auto.7.4. 14541
Zhang, F., Ström, A. L., Fukada, K., Lee, S., Hayward, L. J., and Zhu, H. (2007). Interaction between familial amyotrophic lateral sclerosis (ALS)-linked SOD1 mutants and the dynein complex. J. Biol. Chem. 282, 16691-16699. doi: 10. 1074/jbc.m609743200

Zhang, K. Y., Yang, S., Warraich, S. T., and Blair, I. P. (2014). Ubiquilin 2: a component of the ubiquitin-proteasome system with an emerging role in neurodegeneration. Int. J. Biochem. Cell Biol. 50, 123-126. doi: 10.1016/j.biocel. 2014.02.018

Zhao, K., Luo, G., Giannelli, S., and Szeto, H. H. (2005). Mitochondria-targeted peptide prevents mitochondrial depolarization and apoptosis induced by tertbutyl hydroperoxide in neuronal cell lines. Biochem. Pharmacol. 70, 1796-1806. doi: 10.1016/j.bcp.2005.08.022

Zhao, K., Zhao, G. M., Wu, D., Soong, Y., Birk, A. V., Schiller, P. W., et al. (2004). Cell-permeable peptide antioxidants targeted to inner mitochondrial membrane inhibit mitochondrial swelling, oxidative cell death and reperfusion injury. J. Biol. Chem. 279, 34682-34690. doi: 10.1074/jbc.m4029 99200

Conflict of Interest Statement: The authors declare that the research was conducted in the absence of any commercial or financial relationships that could be construed as a potential conflict of interest.

Copyright (C) 2016 Edens, Miller and Ma. This is an open-access article distributed under the terms of the Creative Commons Attribution License (CC BY). The use, distribution and reproduction in other forums is permitted, provided the original author(s) or licensor are credited and that the original publication in this journal is cited, in accordance with accepted academic practice. No use, distribution or reproduction is permitted which does not comply with these terms. 